\title{
Targeting Runt-Related Transcription Factor 1 Prevents Pulmonary Fibrosis and Reduces Expression of Severe Acute Respiratory Syndrome Coronavirus 2 Host Mediators
}

\author{
Michael O'Hare, * Dhanesh Amarnani, ${ }^{*}$ Hannah A.B. Whitmore, ${ }^{*}$ Miranda An, ${ }^{*}$ Claudia Marino, ${ }^{*}$ Leslie Ramos, ${ }^{*}$ \\ Santiago Delgado-Tirado, ${ }^{*}$ Xinyao Hu, ${ }^{*}$ Natalia Chmielewska, ${ }^{*}$ Anita Chandrahas, ${ }^{*}$ Antonia Fitzek, ${ }^{\dagger}$ Fabian Heinrich, \\ Stefan Steurer, ${ }^{\ddagger}$ Benjamin Ondruschka, ${ }^{\dagger}$ Markus Glatzel, ${ }^{\S}$ Susanne Krasemann, ${ }^{\S}$ Diego Sepulveda-Falla, ${ }^{\S}$ David Lagares, \\ Julien Pedron, "John H. Bushweller, "Paul Liu, ** Joseph F. Arboleda-Velasquez, ${ }^{*}$ and Leo A. Kim*
}

\begin{abstract}
From the Schepens Eye Research Institute of Mass Eye and Ear, * Boston, Massachusetts, and the Department of Ophthalmology at Harvard Medical School, Boston, Massachusetts; the Institutes of Legal Medicine, ${ }^{\dagger}$ Pathology, ${ }^{\ddagger}$ and Neuropathology, ${ }^{\S}$ University Medical Center Hamburg-Eppendorf, Hamburg, Germany; the Division of Pulmonary and Critical Care Medicine, $₫$ Department of Medicine, Massachusetts General Hospital, Harvard Medical School, Boston, Massachusetts; the Department of Molecular Physiology and Biological Physics, "University of Virginia, Charlottesville, Virginia; and the National Institutes of Health, ** National Human Genome Research Institute, Bethesda, Maryland
\end{abstract}

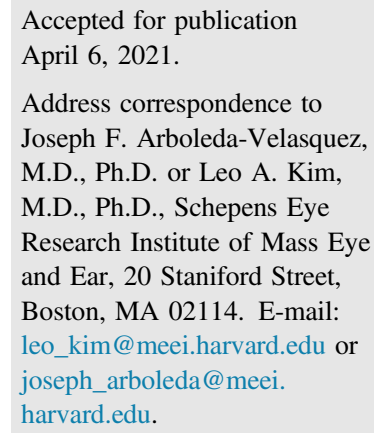

Pulmonary fibrosis (PF) can arise from unknown causes, as in idiopathic PF, or as a consequence of infections, including severe acute respiratory syndrome coronavirus 2 (SARS-CoV-2). Current treatments for PF slow, but do not stop, disease progression. We report that treatment with a runt-related transcription factor 1 (RUNX1) inhibitor (Ro24-7429), previously found to be safe, although ineffective, as a Tat inhibitor in patients with HIV, robustly ameliorates lung fibrosis and inflammation in the bleomycin-induced PF mouse model. RUNX1 inhibition blunted fundamental mechanisms downstream pathologic mediators of fibrosis and inflammation, including transforming growth factor- $\beta 1$ and tumor necrosis factor- $\alpha$, in cultured lung epithelial cells, fibroblasts, and vascular endothelial cells, indicating pleiotropic effects. RUNX1 inhibition also reduced the expression of angiotensin-converting enzyme 2 and FES Upstream Region (FURIN), host proteins critical for SARS-CoV-2 infection, in mice and in vitro. A subset of human lungs with SARS-CoV-2 infection overexpress RUNX1. These data suggest that RUNX1 inhibition via repurposing of Ro24-7429 may be beneficial for PF and to battle SARS-CoV-2, by reducing expression of viral mediators and by preventing respiratory complications. (Am J Pathol 2021, 191: 1193-1208; https://doi.org/10.1016/j.ajpath.2021.04.006)

\footnotetext{
Supported by the Authorities for Social Welfare, Hamburg, Germany, as part of the DEFEAT PANDEMICs project (German Federal Ministry of Education and Research) under grant BMBF 01KX2021 (A.F., F.H. and B.O.); the DEFEAT PANDEMICs project (German Federal Ministry of Education) grants (M.G.); German Center for Infection Research FlexFunds "COVID-19" funding (S.K.); the National Cancer Institute of the NIH under award R01 CA234478 (J.H.B.); the Intramural Research Program, National Human Genome Research Institute, NIH, funding (P.L.); the National Institute of Neurological Disorders and Stroke and National Institutes on Aging cofunded grants NS100121 and NS110048 (J.F.A.-V.); and in part by the National Eye Institute of the NIH under award
}

R01EY027739 (L.A.K.). Research reported in this publication was also supported in part by National Eye Institute/NIH award P30EY003790. We would also like to acknowledge Michel Plantevin for his generous support of this research.

M.O., D.A., and H.A.B.W. contributed equally to this work.

Disclosures: L.A.K. and J.F.A.-V. are listed as inventors in a patent for pulmonary fibrosis and coronavirus disease 2019 treatments. D.L. has a financial interest in Mediar Therapeutics and Zenon Biotech. The companies are developing treatments for organ fibrosis. D.L.'s interests were reviewed and are managed by MGH and Partners HealthCare in accordance with their conflict of interest policies. 
Pulmonary fibrosis (PF) is a chronic and often fatal lung disease characterized by the accumulation of extracellular matrix and the destruction of the lung parenchyma. ${ }^{1-3}$ The cause of PF is unknown in most cases, so is termed idiopathic PF (IPF). IPF is estimated to affect approximately 50 in 100,000 individuals, making IPF the most common interstitial lung disease in the United States, with a median survival of 3 to 5 years after diagnosis. ${ }^{4,5}$

Despite recent developments in antifibrotic drugs, such as nintedanib and pirfenidone, which slow IPF progression, there is still no widely accepted treatment that can reduce mortality in IPF. ${ }^{6}$ There is a dire need to identify therapeutics that modulate key targets in the pathologic mechanisms of lung fibrosis. The repurposing of existing therapeutics with strong safety profiles may provide an accelerated path to identifying much-needed treatments as the incidence of IPF is increasing. ${ }^{7,8}$ It is known that the risk factors for IPF are also risk factors shared with patients infected with severe acute respiratory syndrome coronavirus 2 (SARS-CoV-2), suggesting the possibility that patients with IPF may be at increased risk of severe coronavirus disease 2019 (COVID-19) and associated with an increased mortality. ${ }^{9}$ In addition, the recent SARS-CoV-2 pandemic has the potential to cause a surge of post viral infection induced cases of PF worldwide. ${ }^{10-13}$

Critical pathophysiological mechanisms involved in lung pathology associated with SARS-CoV-2 infection include the following: i) diffuse alveolar damage ${ }^{14,15}$;ii) pulmonary fibrosis ${ }^{11}$; iii) increased vascular leakage/permeability (pulmonary edema) and aberrant angiogenesis ${ }^{16}$; and iv) cytokine storm, in which uncontrolled inflammation leads to the release of an inordinate load of multiple cytokines, leading to morbidity and mortality in patients with COVID19. ${ }^{16,17}$ The most common consequence of COVID-19 in the lung is diffuse alveolar damage, and although pulmonary fibrosis can occur, not all individuals affected with COVID-19 will develop PF. Recent studies suggest that up to $40 \%$ of hospitalized patients with COVID-19 develop acute respiratory distress syndrome and approximately $30 \%$ of these cases develop fibrotic changes. ${ }^{18,19}$ Although remdesivir, dexamethasone, and anti-SARS-CoV-2 antibody cocktails have received emergency approvals for the treatment of COVID-19, there is a critical clinical need for new therapies that can be easily administered and significantly impact clinical outcomes. ${ }^{20-22}$

Runt-related transcription factor 1 (RUNX1) is a transcription factor critical for the process of regulating the differentiation of hematopoietic stem cells during development. ${ }^{23}$ RUNX1 functions as the $\alpha$-DNA-binding component of the transcription factor core-binding factor in association with core-binding factor- $\beta{ }^{24}$ Although RUNX1 is recurrently mutated in sporadic myelodysplastic syndrome and leukemia, core-binding factor- $\beta$ mutations are found in $10 \%$ to $15 \%$ of adult de novo acute myeloid leukemia cases. These links to cancer have generated interest in the discovery and characterization of small-molecule modulators of RUNX1 function, although to date none have been approved for clinical use. ${ }^{25,26}$ RUNX1 functions in tumor necrosis factor (TNF)- $\alpha$-driven proliferation and migration of vascular endothelial cells, driving aberrant angiogenesis in a vascular endothelial growth factor-independent pathway. ${ }^{27,28}$ RUNX1 also functions as a master regulator of epithelial-to-mesenchymal transition via transforming growth factor (TGF)- $\beta 2$ signaling, suppressing epithelial phenotypes and promoting mesenchymal transformation in a blinding condition associated with ocular fibrosis, called proliferative vitreoretinopathy. ${ }^{29}$ These results suggest that RUNX1 activity is associated with both pathologic angiogenesis and fibrosis, key cellular processes found in response to SARS-CoV-2 infection. Thus, RUNX1 modulation may result in novel modalities of treatment for prevalent, nonneoplastic conditions. ${ }^{27}$

Ro24-7429 and Ro5-3335 are small-molecule inhibitors of RUNX1 activity. Ro5-3335 has been widely used in multiple studies as a RUNX1 inhibitor and is commercially available. ${ }^{25}$ Ro24-7429 is of immediate translational interest because it was originally developed and tested in a phase 2 clinical trial for its potential effect as a Tat antagonist in the treatment of AIDS in patients infected with HIV. ${ }^{30}$ Ro24-7429 had an acceptable safety profile in clinical trials but was found to have no detectable antiviral activity. ${ }^{31}$ In this study, we aim to evaluate the role of RUNX1 in lung fibrosis and test the potential antifibrotic effects of Ro24-7429 using the bleomycin-induced model of lung injury. ${ }^{32}$ An increase in RUNX1 RNA was found among a set of genes overexpressed in lung tissue of patients infected with SARS-CoV-2, a screen of differentially expressed angiogenesis-associated genes. $^{16}$ In addition, RUNX1 has recently been predicted to modulate FES Upstream Region (FURIN) and angiotensinconverting enzyme 2 (ACE2) expression based on genomic-guided molecular maps of upstream regulatory elements. ${ }^{33}$ These data indicate that RUNX1 may play an important role during SARS-CoV-2 infection, and through the modulation of RUNX1 it may be possible to repress key host mediators to viral entry. We herein examined a potential direct link between RUNX1 function and the expression of proteins ACE2 and FURIN, two proteins with critical roles in SARS-CoV-2 infection of the lung.

\section{Materials and Methods}

TNF- $\alpha$ and TGF- $\beta 1$ were purchased from PeproTech (Rocky Hill, NJ). RUNX1 inhibitor Ro5-3335 was purchased from Millipore-Sigma (Burlington, MA). We contracted the synthesis of Ro24-7429 as fee for service from MedKoo Biosciences (Morrisville, NC), which confirmed the correct structure by $1 \mathrm{H}$ nuclear magnetic resonance and mass spectrometry, and purity $>99 \%$ by high-performance liquid chromatography (data not shown). The remaining Ro24-7429 was received as a kind gift from Paul Liu 
(National Institutes of Health, National Human Genome Research Institute, Bethesda, MD). The core-binding factor$\beta-$ RUNX1 protein-protein interaction inhibitor, AI-14-91, was synthesized as described previously ${ }^{19}$ and was received as a kind gift from the Bushweller Lab (Department of Molecular Physiology and Biological Physics, University of Virginia, Charlottesville, VA).

\section{Animal Model}

Animal procedures were approved by the Institutional Animal Care and Use Committee of Massachusetts Eye and Ear, and performed in accordance with the Association for Research in Vision and Ophthalmology Statement for the Use of Animals in Ophthalmic and Vision Research. C57BL/6J male and female mice, aged 6 to 8 weeks, were purchased from Jackson Laboratory (Bar Harbor, ME). For all procedures, mice were anesthetized by i.p. injection of ketamine/xylazine mixture $(100 / 50 \mathrm{mg} / \mathrm{kg})$.

\section{Experimental Design}

Bleomycin sulfate (Sigma-Aldrich, St. Louis, MO) was dissolved in sterile $0.9 \%$ saline and administered as a single dose of 0.05 units in a total volume of $50 \mu \mathrm{L}$ in saline solution per animal intratracheally. Control animals received $0.05 \mathrm{~mL}$ saline alone. A preventative regimen was chosen, and each animal received either Ro24-7429 drug, $70 \mathrm{mg} / \mathrm{kg}$, or vehicle every other day for 7 days before the induction of the model and continued until the end of the experiment for 1 or 2 weeks. All animals received intratracheal instillations of bleomycin on day 0 , as previously described. ${ }^{34-37} \mathrm{~A}$ separate experiment was performed with similar drugvehicle treatments and intratracheal saline instillation for controls. The surgeon performing intratracheal instillations was masked to the identity of the treatment groups. Mice were sacrificed at day 7 or day 14 after bleomycin instillations, and mouse lungs were perfused with phosphatebuffered saline to inflate the lungs before fixation.

\section{Morphologic Examination}

Lung tissue sections were fixed in $10 \%$ neutral-buffered formalin (Sigma-Aldrich; HT501128-4L) for 24 hours for histologic analysis. Fixed lungs were paraffin embedded and sectioned $(5 \mu \mathrm{m}$ thick), stained with hematoxylin and eosin to examine gross morphology and Masson trichrome stain to visualize collagen deposition, and examined by microscopy. Lung fibrosis was measured using quantitative histology using the Ashcroft method of analysis. All measurements were performed by two independent graders (N.C., A.C.) in a blinded manner. Images were acquired with the Nikon Eclipse E800 microscope (Minato City, Tokyo, Japan) with an Olympus DP70 camera (OM Digital Solutions, Hachioji, Tokyo, Japan). Adjacent $2 \times$ images of the lung were stitched together using Adobe Photoshop CS6 (San Jose, CA).

\section{Immunofluorescence Analysis of Lung Tissue}

Paraffin-embedded sections were processed for immunofluorescence using the following antibodies: anti-RUNX1 (1:100; LS-B13948; Lifespan Biosciences, Seattle, WA), anti- $\alpha$-smooth muscle actin (SMA) antibody (1:200; A2547; Millipore-Sigma), anti-ionized calcium binding adaptor molecule 1 (Iba1) antibody (1:100; ab5076; Abcam, Cambridge, UK), anti-Ly6g antibody (1:100; ab25377; Abcam), and Isolectin GS-IB4 Alexa Fluoro 594 Conjugate (1:250; 121413; Invitrogen, Carlsbad, CA). For heat-induced antigen retrieval, the slides were boiled in $10 \mathrm{mmol} / \mathrm{L}$ sodium citrate buffer ( $\mathrm{pH}$ 6.0) and then maintained at a subboiling temperature $\left(95^{\circ} \mathrm{C}\right.$ to $\left.100^{\circ} \mathrm{C}\right)$ for 20 minutes and subsequently cooled on the bench top for 30 minutes. Slides were washed with distilled water, permeabilized with $0.5 \%$ Triton X-100 in phosphate-buffered saline for 5 minutes, and blocked (10\% goat serum in phosphate-buffered saline) for 1 hour at room temperature. The primary antibody was prepared in antibody dilution buffer (5\% goat serum), and samples were incubated overnight with the antibody solution at $4^{\circ} \mathrm{C}$. Sections were washed with phosphate-buffered saline and incubated with goat anti-rabbit Alexa Fluor 594 secondary antibody (1:500; A-11012; Invitrogen) for 2 hours at room temperature. Slides were mounted and visualized using Prolong Gold Antifade Reagent with DAPI (P36935; Invitrogen). Images were obtained using an EVOS FL automated stage live cell imaging system (Life Technologies, Cambridge, MA).

\section{Transmission Electron Microscopy}

Mouse lungs were perfused with saline and fixed with half strength Karnovsky fixative ( $2 \%$ formaldehyde $+2.5 \%$ glutaraldehyde, in $0.1 \mathrm{~mol} / \mathrm{L}$ sodium cacodylate buffer, $\mathrm{pH}$ 7.4) for 24 hours under refrigeration. After fixation, samples were trimmed into 1 -mm thick segments, rinsed with 0.1 $\mathrm{mol} / \mathrm{L}$ sodium cacodylate buffer, post-fixed with $2 \%$ osmium tetroxide in $0.1 \mathrm{~mol} / \mathrm{L}$ sodium cacodylate buffer for 1.5 hours, en bloc stained with $2 \%$ gadolinium triacetate in $0.05 \mathrm{~mol} / \mathrm{L}$ sodium maleate buffer, $\mathrm{pH} 6$, for 30 minutes, then dehydrated with graded ethyl alcohol solutions, transitioned with propylene oxide, and infiltrated in tEPON-812 epoxy resin (Tousimis, Rockville, MD) utilizing an automated EMS Lynx 2 EM tissue processor (Electron Microscopy Sciences, Hatfield, PA). The processed samples were oriented into tEPON-812 epoxy resin inside flat molds and polymerized using a $60^{\circ} \mathrm{C}$ oven. Semithin and ultrathin sections were obtained using a Leica UC7 ultramicrotome (Leica Microsystems, Buffalo Grove, IL) and diamond knives (Diatome, Hatfield, PA). Semithin sections were cut at $1 \mu \mathrm{m}$ thickness through different lobes stained with $1 \%$ toluidine blue in $1 \%$ sodium tetraborate aqueous solution for 
assessment by light microscopy. Ultrathin sections on grids were stained with aqueous $2.5 \%$ gadolinium triacetate and modified Sato lead citrate. Grids were imaged using an FEI Tecnai G2 Spirit transmission electron microscope (FEI, Hillsboro, OR) at $80 \mathrm{kV}$ interfaced with an AMT XR41 digital charge-coupled device camera (Advanced Microscopy Techniques, Woburn, MA) for digital TIFF file image acquisition. Transmission electron microscopy digital images were captured at $2000 \times 2000$ pixels at 16-bit resolution.

\section{Cell Culture}

Human alveolar epithelial cells (A549) were a generous gift from Dr. David Lagares (Massachusetts General Hospital, Boston, MA). Cells were maintained in low-glucose Dulbecco's modified Eagle's medium containing $10 \%$ fetal bovine serum, $2 \mathrm{mmol} / \mathrm{L}$ L-glutamine, $100 \mathrm{U} / \mathrm{mL}$ penicillin, and 100 $\mu \mathrm{g} / \mathrm{mL}$ streptomycin at $37^{\circ} \mathrm{C}$ in a humidified $5 \% \mathrm{CO}_{2}$ atmosphere. Confluent cultures of cells were pretreated with Ro247429 for 24 hours, followed by stimulation with $5 \mathrm{ng} / \mathrm{mL}$ of TGF- $\beta 1$. Human lung fibroblasts (HLFs) were also a kind gift from Dr. David Lagares. Cells were maintained as above before treatment with Ro24-7429 and nintedanib for 72 hours.

Human microvascular endothelial cells (lung) (HMEC-Ls; CC-2527) purchased at Passage 1 from Lonza (Basel, Switzerland) were incubated at $37^{\circ} \mathrm{C}$ with $5 \% \mathrm{CO}_{2}$. HMEC-Ls were plated at Passage 2-6 using endothelial growth media (EGM-2; Lonza) supplemented with EGMTM-2 MV Microvascular Endothelial Cell Growth Medium-2 BulletKit (CC2527). Cells were treated at Passage 3-7 in endothelial basal media (EBM-2; Lonza) supplemented with 5\% fetal bovine serum, $1 \%$ gentamicin/amphotericin, and selected stimulants.

Human pulmonary alveolar epithelial cells were purchased from ScienCell (Carlsbad, CA) and cultured in alveolar epithelial cell medium (ScienCell) supplemented with $2 \%$ fetal bovine serum, epithelial cell growth supplement, $100 \mathrm{U} / \mathrm{mL}$ penicillin $\mathrm{G}$, and $100 \mu \mathrm{g} / \mathrm{mL}$ streptomycin. The cells were cultured and maintained in 6-well plates for experimental purposes.

\section{oPOSSUM Analysis}

Angiogenesis-associated genes in COVID-19 deceased patients were previously reported. ${ }^{16}$ Analysis of this gene set was performed using oPOSSUM version 3.0 (http:// opossum.cisreg.ca, last accessed June 1, 2021), human single site analysis tool with either RUNX1 or activator protein 1 (AP-1) as the JASPAR CORE transcription factor binding site (TFBS) profile. Conservation cutoff was 0.4 ; matrix score threshold was $85 \%$; and upstream/ downstream sequence was 5000. Target gene hits shared between AP-1 and RUNX1 were manually compared, whereas genes associated with the c-Jun $\mathrm{N}$-terminal kinase (JNK) pathway were manually matched with JNK signaling pathway genes reported by AmiGO 2 (http:// amigo.geneontology.org/amigo, last accessed April 13, 2021).

\section{Human Tissue Immunohistochemistry}

All autopsies of SARS-CoV-2 infected deceased were performed at the Institute of Legal Medicine, University Medical-Center of Hamburg-Eppendorf, as described in previous works, ${ }^{37}$ between March and September 2020 in the dissection room, with institutional review board approval from the independent ethics committee of the Hamburg University (protocol PV7311). Seven COVID-19 patients and one case with negative PCR virus test were selected. Clinical data, including pre-existing medical conditions, medical course before death, and antemortem diagnostic findings, were assessed (Supplemental Table S1). Lung tissue samples were formalin fixed and paraffin embedded. Samples were immunohistochemically stained using a Ventana Benchmark XT Autostainer (Ventana, Tucson, AZ). RUNX1 staining was performed in accordance with the manufacturer's recommendations, using a RUNX1 antibody (HPA004176; rabbit polyclonal; Sigma Aldrich, Hamburg, Germany; dilution 1:200). For detection of specific binding, the Ultra View Universal 3,3'-Diaminobenzidine Detection Kit (Ventana, Roche, Basel, Switzerland) was used, which contains secondary antibodies, 3,3'-diaminobenzidine stain, and counterstaining reagent. Slides were examined and diagnosed by an experienced lung pathologist (S.S.). Whole slides were then electronically scanned at high magnification $(\times 40)$ as highresolution images $(1900 \times 1200$ pixels $)$ with a NanoZoomer 2.0-HT (Hamamatsu Photonics, Hamamatsu, Japan).

\section{Western Blot Analysis}

Protein concentration was determined by Pierce bicinchoninic acid protein assay kit (ThermoFisher, Waltham, MA; 23227), according to the manufacturer's instructions. A total of $20 \mu \mathrm{g}$ of total cell lysates was prepared in $4 \mu \mathrm{L} 1 \mathrm{~mol} / \mathrm{L}$ 1,4-dithiothreitol (Sigma Aldrich) and $10 \mu \mathrm{L}$ Laemmli buffer (Boston Bioproducts, Ashland, MA) to a final volume of $40 \mu \mathrm{L}$ and denatured for 5 minutes at $90^{\circ} \mathrm{C}$. Samples were separated electrophoretically for 1 hour at $70 \mathrm{~V}$ using $4 \%$ to $20 \%$ precast gradient gels (MiniPROTEAN TGX; Bio-Rad, Hercules, CA) and SDS-Tris-Glycine buffer (Bio$\mathrm{Rad})$. Proteins were transferred to $0.45-\mu \mathrm{m}$ nitrocellulose membranes for 1 hour at $70 \mathrm{~V}$ in ice-cold $20 \%$ Methanol Tris-Glycine buffer (Bio-Rad). Membranes were blocked for 1 hour with Odyssey Blocking Buffer (LI-COR Biosciences, Lincoln, NE). Then, they were incubated with primary antibodies anti-N-cadherin (1:500; sc-53488; Santa Cruz Biotechnology, Dallas, Tx), anti-RUNX1 (1:100; LS-B13948; Lifespan Biosciences, Seattle, WA), and anti- $\alpha$-SMA antibody (1:200; A-2547; MilliporeSigma) for 3 hours at room temperature or overnight at $4^{\circ} \mathrm{C}$ and then washed $3 \times$ with Tris-buffered saline with 
Tween 20 and incubated with secondary antibodies IRDye $800 \mathrm{CW}$ donkey anti-mouse or IRDye 680RD donkey antirabbit (Li-cor, Lincoln, NE) for 1 hour and washed $3 \times$ with Tris-buffered saline with Tween 20. Immunoreactive bands were detected using the Odyssey Infrared Imaging System and visualized on the Image Studio version 2.1 software (LICOR Biosciences).

\section{RT-qPCR Data}

HMEC-Ls were plated and treated, as described above, for between 24 and 72 hours. The time point of quantitative quantitative reverse transcription polymerase chain reaction (RT-qPCR) lysis collection when not specified is 48 hours of treatment. RNA was extracted using RNeasy Mini Kits (Qiagen, Hilden, Germany), as per the manufacturer's instructions. Transcription into cDNA was performed using the iScript cDNA synthesis kit (Bio-Rad), following the manufacturer's protocol, and probed using FastStart Universal SYBR Green Master Mix (Hoffmann-La Roche, Basel, Switzerland) in 384-well white plates.

Mice were treated, as described previously, before euthanasia. Lung samples were collected for RT-qPCR analysis, and tissues were lysed by homogenization. RNA was extracted using RNeasy Mini Kits, as per the manufacturer's instructions for tissue samples. Transcription into cDNA and analysis were performed as stated previously. Primers for selected genes (Table 1) were purchased from Integrated DNA Technologies (Coralville, IA).

\section{Statistical Analysis}

Results are presented as means \pm SEM. Data were assessed with analysis of variance (one-way analysis of variance) followed by the Dunnett multiple comparisons test. Twotailed unpaired $t$-test was used for comparisons between two groups. Values with statistical significance are indicated as $* P<0.05, * * P<0.01$, and $* * * P<0.01$.

\section{Results}

\section{Dose-Dependent Antifibrotic Activity of the RUNX1 Inhibitor Ro24-7429}

Bleomycin triggers a strong inflammatory response in the lung at day 7 , characterized by infiltration with neutrophils and macrophages, vascular leakage, and up-regulation of cytokines, chemokines, and other inflammatory mediators. By day 14, bleomycin-treated mice are expected to develop significant lung fibrosis, including disruption of the normal lung architecture, thickening of the alveolar septa, and excessive extracellular matrix and collagen deposition around the alveolar structures. We examined the effects of escalating doses of Ro24-7429 (17.5, 35, and $70 \mathrm{mg} / \mathrm{kg}$ per day) on bleomycin-induced lung fibrosis by hematoxylin and eosin and Masson trichrome staining in mice at day 14 (Figure 1, A and B, and Supplemental Figure S1). These doses were estimated to be equivalent to those used in the Ro24-7429 human trial $(75,150$, or $300 \mathrm{mg}$ per day, respectively). ${ }^{31}$ We initiated treatment 1 week before intratracheal instillation of bleomycin because treatments for COVID-19 appear to be more effective at early stages before the disease significantly alters pulmonary function and because future clinical trials may be more feasible under a preventative therapy paradigm.

Prominent areas of dense fibrotic foci were detected 2 weeks after bleomycin instillation using Masson trichrome staining and confirmed by transmission electron microscopy (Figure 1, A-C). Conversely, mice treated with Ro24-7429 (70 $\mathrm{mg} / \mathrm{kg}$ ) displayed robust preservation of lung structures after bleomycin instillation, similar to mice instilled with intratracheal saline (Figure 1, A and B, and Supplemental Figure S1). Fewer to no areas of fibrosis were observed in the Ro24-7429-treated mice, as confirmed by a significant reduction in the Ashcroft fibrosis score (Figure 1D). A dosedependent effect of the drug was observed on the lung

Table 1 Primer Sequences Used in RT-qPCR Analysis

\begin{tabular}{|c|c|c|c|}
\hline Primer & Species & Forward & Reverse \\
\hline HPRT1 & Human & $5^{\prime}$-АСССТTTCCAAATCСТCAGC-3' & $5^{\prime}$-GTTATGGCGACCCGCAG-3' \\
\hline RUNX1 & Human & $5^{\prime}-\mathrm{TCCACAAACCCACCGCAAGT-3^{ \prime }}$ & $5^{\prime}-$ CGCTCGGAAAAGGACAAGC- $3^{\prime}$ \\
\hline ACE2 & Human & $5^{\prime}-\mathrm{ACAGTCCACACTTGCCCAAAT-3^{ \prime }}$ & $5^{\prime}-\mathrm{TGAGAGCACTGAAGACCCATT-3^{ \prime }}$ \\
\hline HPRT1 & Mouse & $5^{\prime}-$ TCAGTCAACGGGGGACATAAA-3' & 5'-GGGGCTGTACTGCTTAACCAG-3' \\
\hline RUNX1 & Mouse & $5^{\prime}-$ TGGTGGAGGTACTAGCTGACC-3' & 5'-CGAGTAGTTTTCATCGTTGCCTG-3' \\
\hline$\alpha$-SMA & Mouse & $5^{\prime}$-GTCCCAGACATCAGGGAGTAA-3' & 5'-TCGGATACTTCAGCGTCAGGA-3' \\
\hline TNF-R1 & Mouse & 5'-GGGCACCTTTACGGCTTCC-3' & $5^{\prime}-$ TCTCCTTACAGGGGATTGTCAC-3' \\
\hline TGF- $\beta 1$ & Mouse & 5'-CTCCCGTGGCTTCTAGTGC-3' & 5'-GCCTTAGTTTGGACAGGATCTG-3' \\
\hline Fibronectin & Mouse & $5^{\prime}$-ATGTGGACCCCTCCTGATAGT-3' & 5'-GCCCAGTGATTTCAGCAAAGG-3' \\
\hline Collagen & Mouse & $5^{\prime}$-CTGTAACATGGAAACTGGGGAAA-3' & 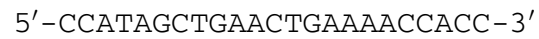 \\
\hline
\end{tabular}

ACE2, angiotensin-coverting enzyme 2; FURIN, FES upstream region; HPRT1, hypoxanthine phosphoribosyltransferase 1; RT-qPCR, quantitative RT-PCR; RUNX1, runt-telated transcription factor $1 ; \alpha$-SMA, $\alpha$-smooth muscle actin; TGF- $\beta 1$, transforming growth factor- $\beta 1 ;$ TNF-R1, tumor necrosis factor receptor 1. 
A

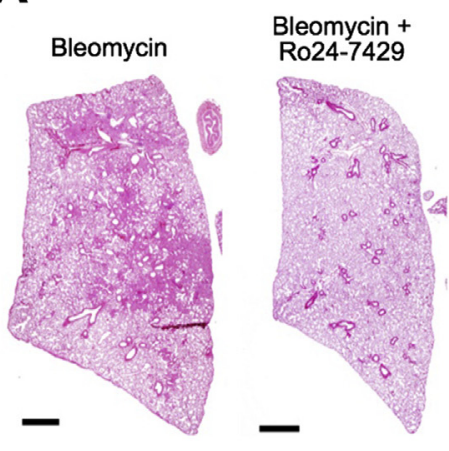

D

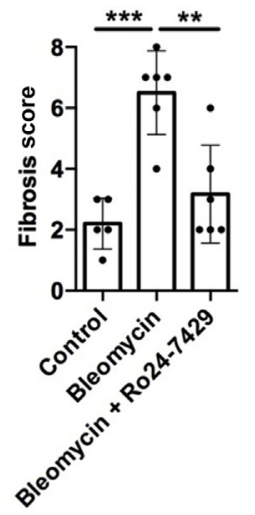

G

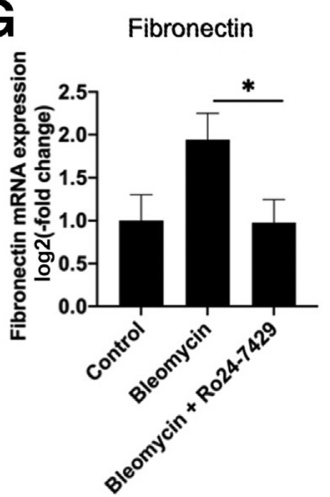

H Bleomycin $\begin{array}{r}\text { Bleomycin }+ \\ \text { Ro24-7429 }\end{array}$

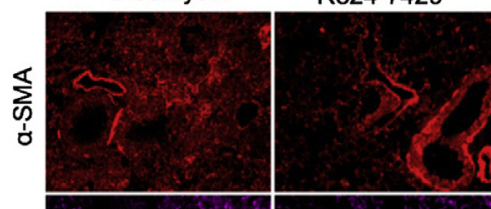

产

1

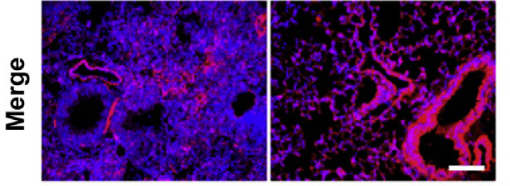

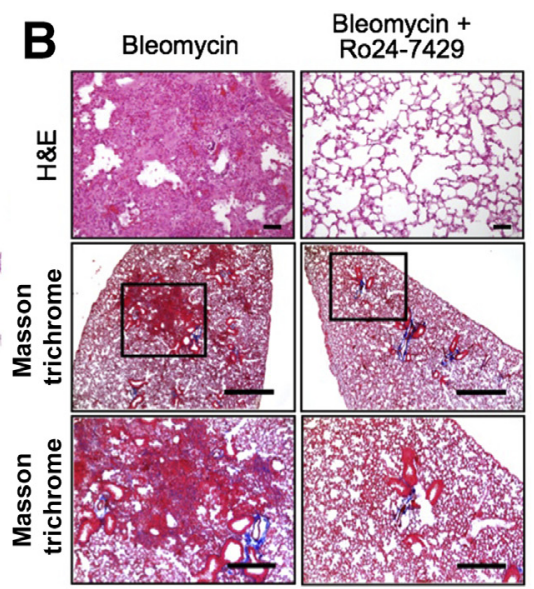

F

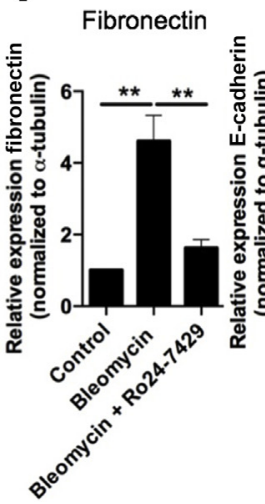

E-cadherin

RUNX1
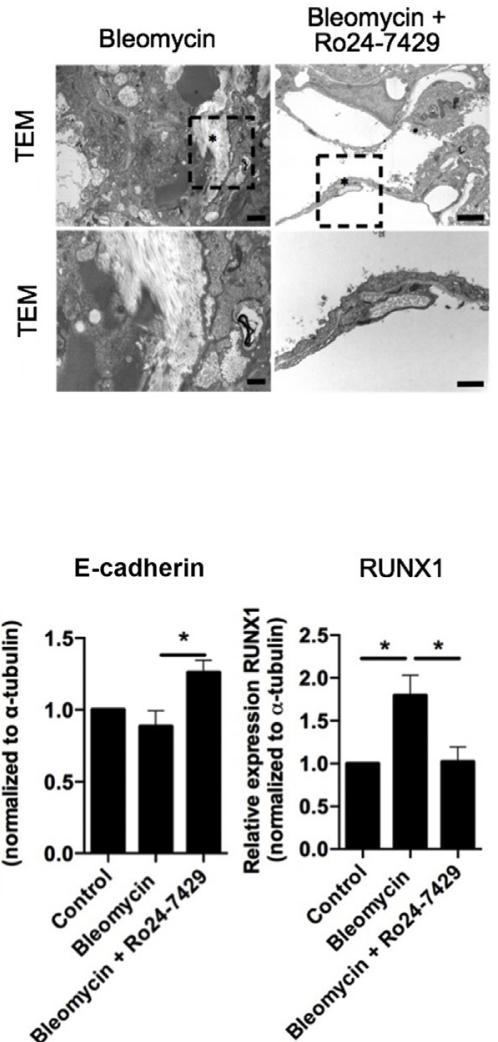

RUNX1

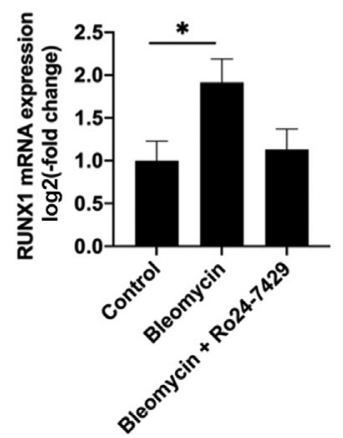

a-SMA

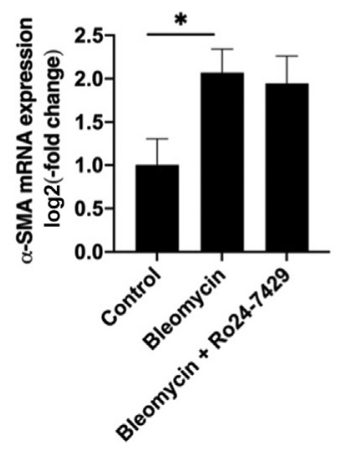

Bleomycin +

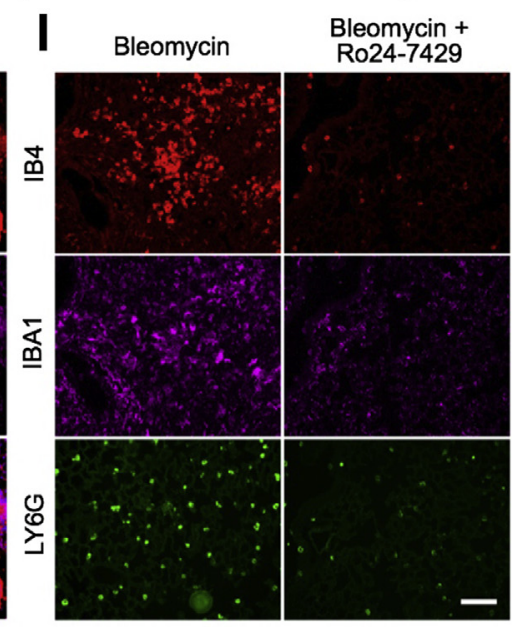

J

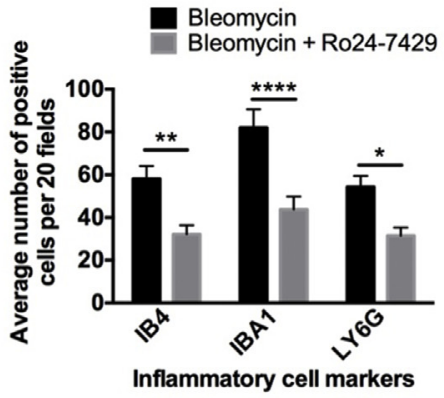


phenotype with the lowest dose $(17.5 \mathrm{mg} / \mathrm{kg})$, showing slight effect, whereas the $35 \mathrm{mg} / \mathrm{kg}$ dose showed a moderate but variable effect on the progression of fibrosis (Supplemental Figure S1).

\section{RUNX1 Inhibition Curbs Expression of Fibrosis Markers in Injured Mouse Lungs}

We evaluated the expression of RUNX1 and known markers of fibrosis in lung tissue of mice instilled with bleomycin treated with Ro24-7429 or vehicle. As expected, Western blot analysis showed that Ro24-7429 treatment reduced the expression of RUNX1 and fibronectin, whereas it preserved the expression of E-cadherin, an epithelial marker (Figure 1, E and F). RT-qPCR analysis showed up-regulation of mRNA expression for fibrosis markers, including $\alpha$-SMA, collagen $3 \mathrm{~A} 1$, and fibronectin, in lung tissue of mice instilled with bleomycin compared with tissues from the saline control group (Figure 1G). Immunofluorescence staining and RT-qPCR revealed a significant up-regulation of RUNX1 on induction of fibrosis after bleomycin instillation (Figure 1, G and $\mathrm{H})$. This effect on RUNX1 up-regulation observed in bleomycin-injured mice was significantly attenuated in mice treated with Ro24-7429. Ro24-7429 treatment also blunted the up-regulation of fibrosis markers triggered by bleomycin compared with vehicle-treated mice (Figure 1, E-H).

The protective effects of the highest dose of Ro24-7429 $(70 \mathrm{mg} / \mathrm{kg}$ ) were further supported by immunostaining analysis of $\alpha$-SMA, a marker of scar-forming myofibroblasts, which colocalized within dense fibrotic regions in the bleomycin instilled lungs but was localized only to vessels (staining mural cells), as expected, in the Ro247429-treated mice (Figure 1H).

\section{Anti-Inflammatory Activity of Ro24-7429}

We evaluated the potential effect of Ro24-7429 on bleomycin-induced inflammation 1 and 2 weeks after lung injury (Figures 1, I and J, and 2). As expected, bleomycin did not trigger significant fibrosis at the 1-week time point (Figure 2, A-G). As shown in Figures 1, I and J, and 2, H and I, a large influx of neutrophils and macrophages was observed in the bleomycin-injected mice. Mice treated with Ro24-7429 showed reduced infiltration of inflammatory cells, specifically neutrophils and macrophages, at the 1and 2-week time points. These results indicated that RUNX1 inhibition robustly abrogated lung fibrosis and inflammation in a bleomycin injury model.

\section{RUNX1 Regulates Proliferation and TGF- $\beta 1$-Induced Fibrosis in Cultured Lung Cells}

We conducted mechanistic studies in cell culture to examine the cellular and molecular mechanisms underlying the robust effects of RUNX1 inhibition in the protection against bleomycin-induced lung injury. We tested the effect of RUNX1 inhibition on the proliferation of human alveolar epithelial cells (A549), primary human-derived pulmonary alveolar epithelial cells, and human-derived primary culture lung fibroblasts (HLFs). For specific analyses, we used escalating doses of Ro24-7429 (50 to $200 \mu \mathrm{mol} / \mathrm{L}$ ), Ro5$3335(150 \mu \mathrm{mol} / \mathrm{L})$, pirfenidone $(500 \mu \mathrm{g} / \mathrm{mL})$, and nintedanib $(5 \mu \mathrm{mol} / \mathrm{L})$; the latter two are currently approved drugs for IPF.

Ro24-7429 strongly inhibited the proliferation of A549 and HLF cells in a dose-dependent manner, as measured by the CyQUANT Direct Cell Proliferation Assay (ThermoFisher, Waltham, MA) (Supplemental Figure S2, A-C). Low levels of cell death were detected by lactate dehydrogenase analysis at concentrations of Ro24-7429 (50 to 200 $\mu \mathrm{mol} / \mathrm{L})$ and Ro5-3335 $(150 \mu \mathrm{mol} / \mathrm{L})$ in both the cell types, suggesting a direct effect in proliferation by RUNX1 inhibition (Supplemental Figure S2, D-F). At 48 hours, Ro247429 treatment significantly reduced proliferation in A549 cells by $68 \%$ at the highest concentration $(200 \mu \mathrm{mol} / \mathrm{L})$, with $62 \%$ reduction with the lowest concentration $(50 \mu \mathrm{mol} /$ L). We observed further reduction in proliferation at 72 hours with an $82 \%$ reduction $(200 \mu \mathrm{mol} / \mathrm{L})$. A similar significant effect was observed on proliferation in HLF cells. At 72 hours, Ro24-7429 at the highest concentration (200 $\mu \mathrm{mol} / \mathrm{L}$ ) caused a $55 \%$ reduction in proliferation. A $30 \%$ reduction in proliferation was observed at the lowest concentration $(50 \mu \mathrm{mol} / \mathrm{L})$. Ro5-3335 also exhibited a strong antiproliferative effect at 48 hours (32\%) and 72 hours $(50 \%)$ in A549 cells. We also observed a similar robust effect of Ro5-3335 in HLF cells, resulting in a 40\% reduction in proliferation at 72 hours. The effect of Ro247429 on proliferation was robust and of similar magnitude compared with that of nintedanib and pirfenidone. However, pirfenidone $(500 \mu \mathrm{g} / \mathrm{mL})$ caused significant cell death $(8 \%)$

\footnotetext{
Figure 1 Antifibrotic and anti-inflammatory effect of Ro24-7429 at day 14 in the bleomycin model of pulmonary fibrosis. A and B: Histologic images and collagen deposition of the lung tissue were assessed by hematoxylin and eosin (H\&E) and Masson trichrome staining and visualized using bright-field microscopy. Boxed areas indicate areas magnified below. C: Representative transmission electron microscopy (TEM) micrographs at low magnification (top panels) and high magnification (bottom panels) of bleomycin- and Ro24-7429-treated lungs on day 14. Dotted boxed areas indicate areas magnified below. D: Fibrosis score. E and F: Detection and quantification of RUNX1, E-cadherin, and fibronectin levels by Western blot analysis in bleomycin- and Ro24-7429-treated lungs. G: Quantitative RT-PCR analysis of mRNA levels of fibronectin, collagen 3A1, RUNX1, and $\alpha$-SMA in bleomycin- and Ro24-7429-treated lungs. $\mathbf{H}$ and I: Immunohistochemistry on paraffin sections for $\alpha$-smooth muscle actin ( $\alpha$-SMA), RUNX1, IBA1, IB4, and LY6G. J: Quantification of IB4-, IBA1-, and LY6G-positive cells in bleomycin- and Ro247429-treated lungs. All data are presented as means $\pm \operatorname{SEM}(\mathbf{D}, \mathbf{F}, \mathbf{G}$, and $\mathbf{J}) . n=5$ to $6(\mathbf{D}, \mathbf{F}, \mathbf{G}$, and $\mathbf{J}) .{ }^{*} P<0.05,{ }^{*} P<0.01,{ }^{* * *} P<0.001$, and $* \star * * P<0.0001$. Scale bars: $50 \mu \mathrm{m}$ (A); $1000 \mu \mathrm{m}$ (B); $2 \mu \mathrm{m}$ (C, top panels); $500 \mu \mathrm{m}$ (C, bottom panels); $100 \mu \mathrm{m}$ (H and I).
} 

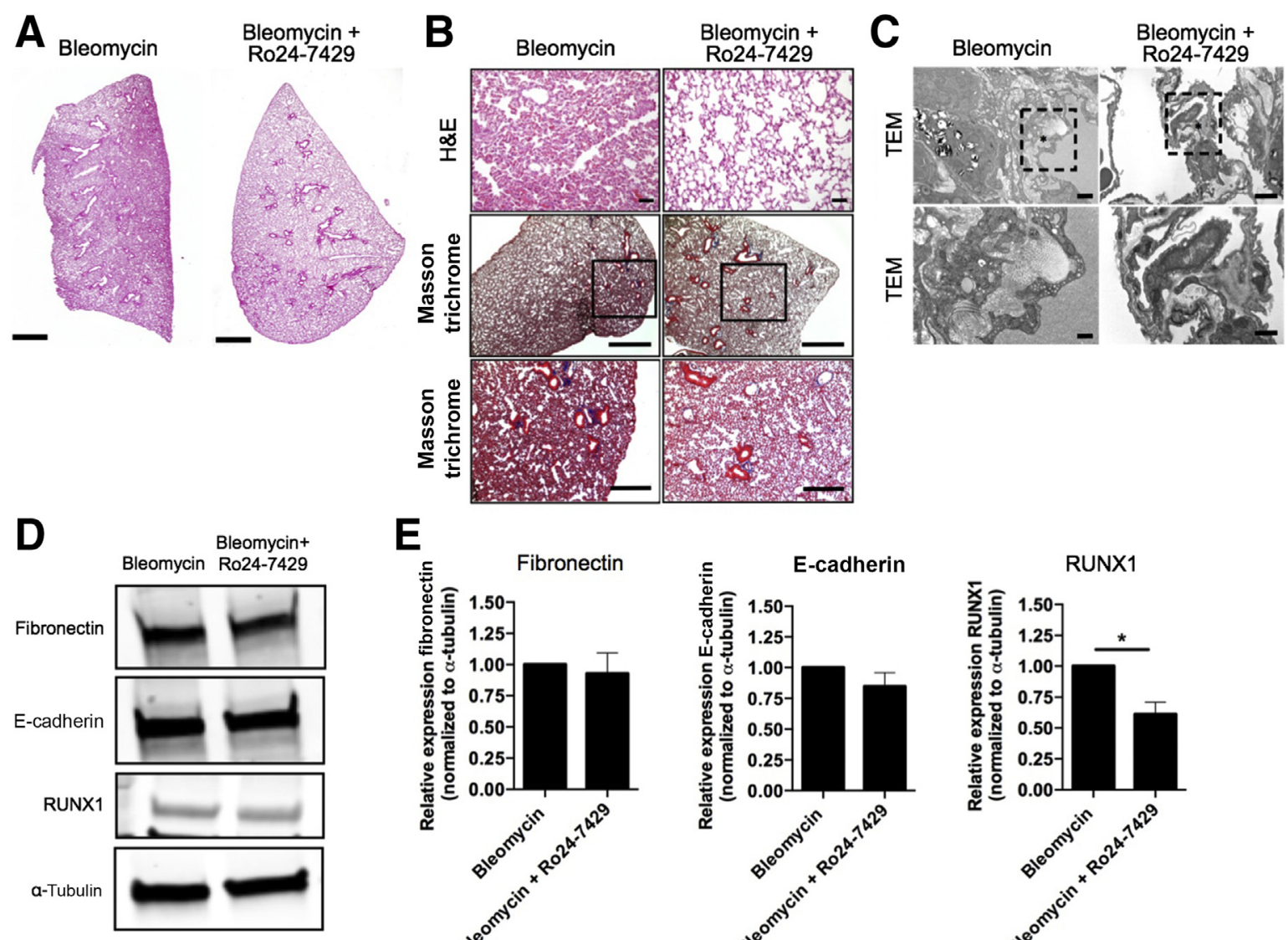

E
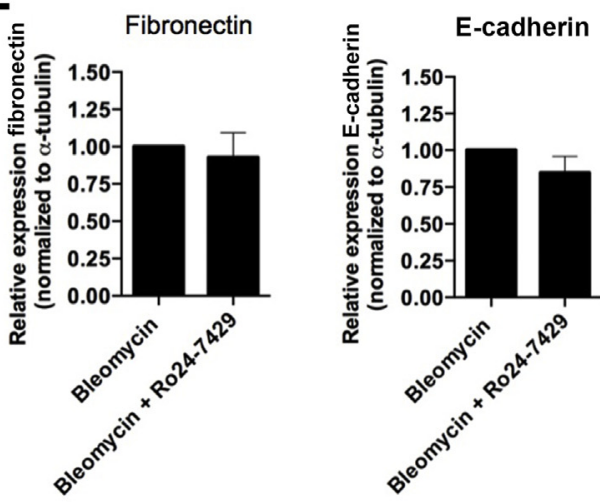

RUNX1

F
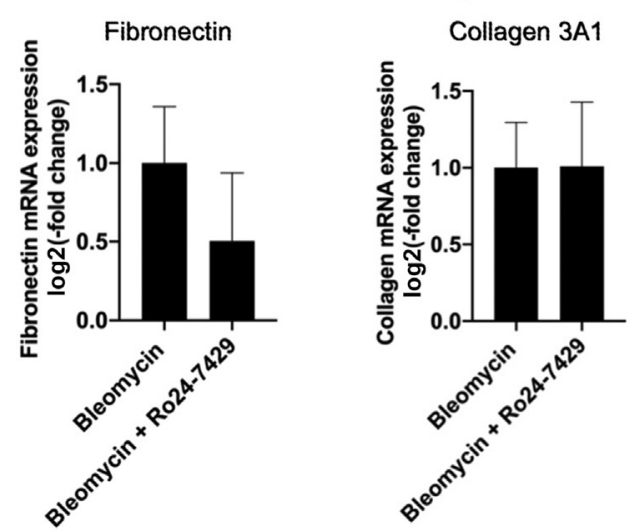

RUNX1
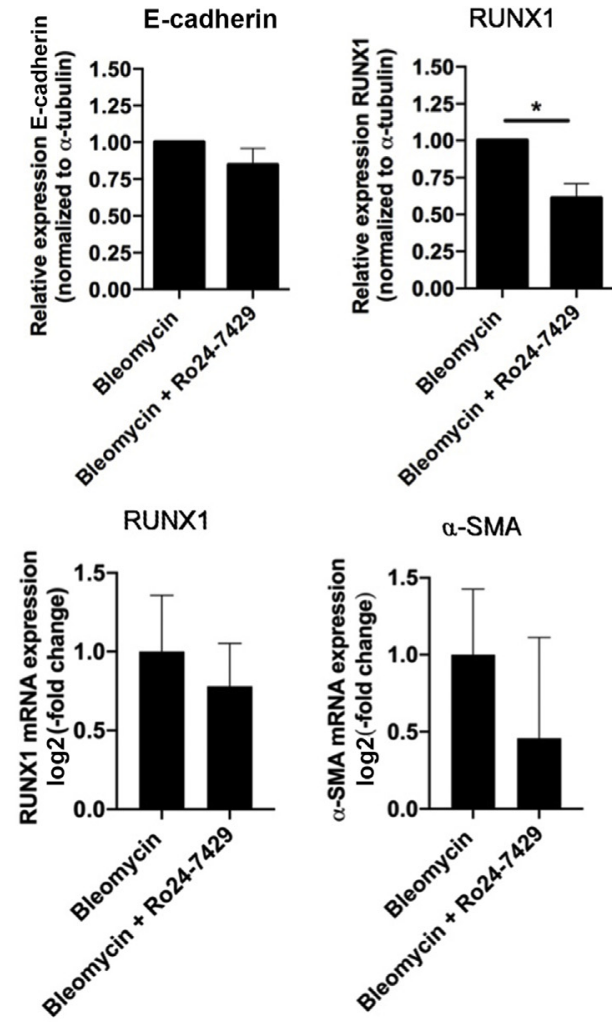

Collagen 3A1

\section{a-SMA}
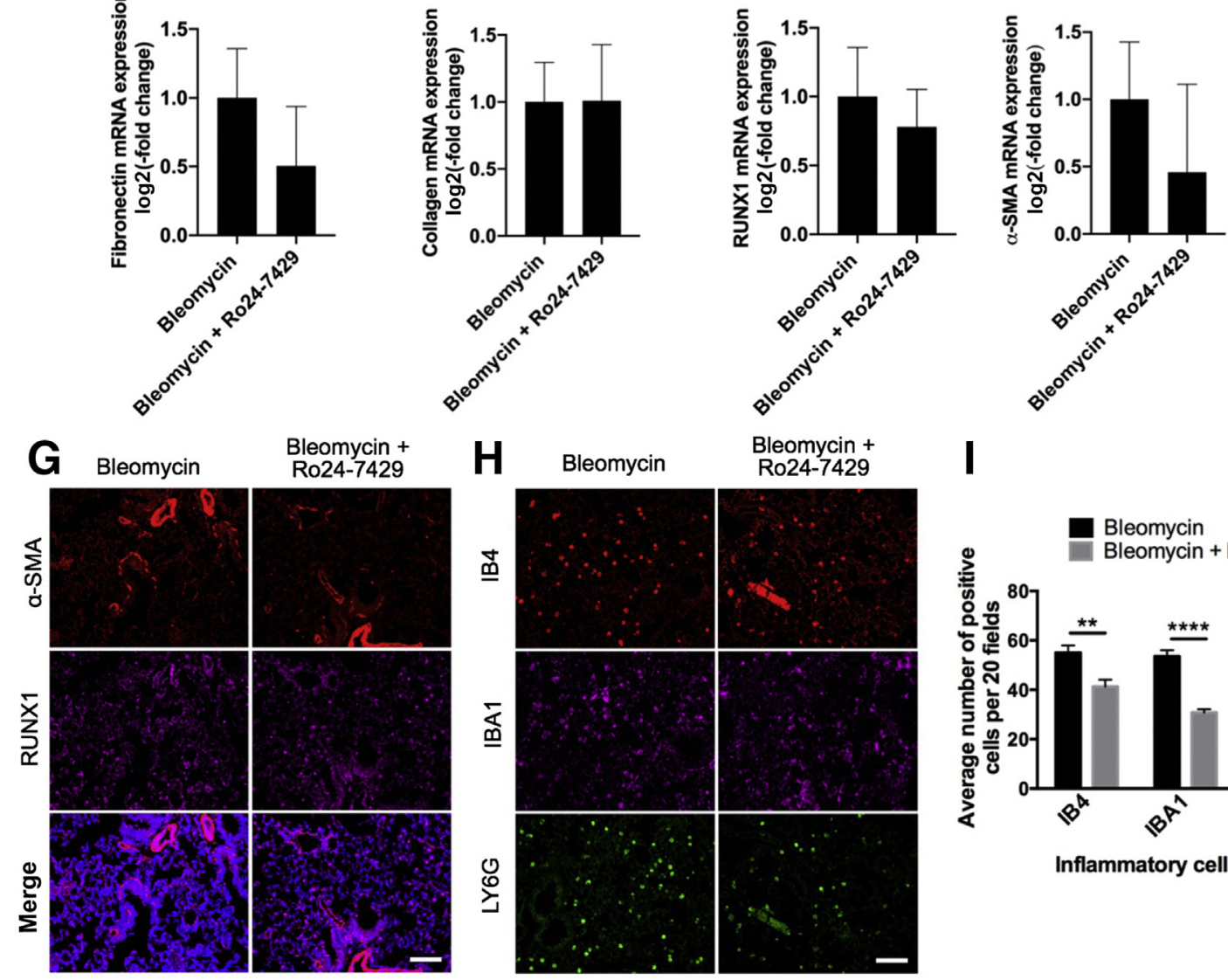

I

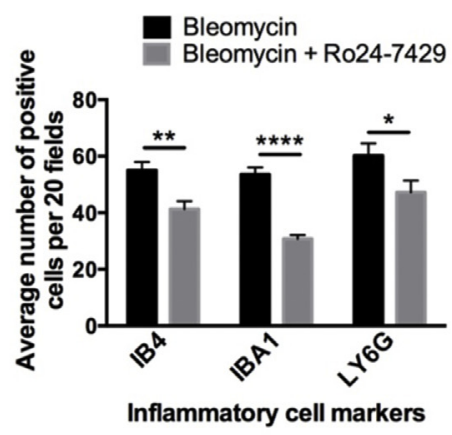


at 48 hours, which increases to $11 \%$ at 72 hours in A549 cells (Supplemental Figure S2, D and E).

We evaluated the effect of RUNX1 inhibition on the expression of fibrosis markers induced by TGF- $\beta 1$, a critical mediator of $\mathrm{PF},{ }^{38}$ in A549 cells at 24, 48, and 72 hours. We found that TGF- $\beta 1$ exposure strongly induced the expression of $\alpha$-SMA and N-cadherin in A549 cells using RT-qPCR (Figure 3A) and Western blot analyses (Figure 3, B and $\mathrm{C}$ ) at all three time points after exposure. RUNX1 expression was also strongly induced by TGF- $\beta 1$ exposure at 24, 48, and 72 hours (Figure 3, A-C). We found that RUNX1 inhibition with Ro24-7429 (150 and $200 \mu \mathrm{mol} / \mathrm{L}$ ) administered 24 hours before TGF$\beta 1$ exposure effectively prevented TGF- $\beta 1$-induced $\mathrm{N}$ cadherin up-regulation in A549 cells and human-derived pulmonary alveolar epithelial cells using Western blot analysis (Figure 3, D-G). We concluded that modulation of TGF- $\beta 1-$ mediated effects on lung fibrosis in lung epithelial cells is a potential mechanism explaining the robust impact of RUNX1 inhibition on the outcomes of bleomycin-induced lung injury.

\section{TNF- $\alpha$ Significantly Increased RUNX1 Expression in Primary Lung Endothelial Cells}

Proinflammatory mediators, such as TNF- $\alpha$, are increased in the inflammatory phase of tissue injury leading to fibrosis. ${ }^{39}$ This cytokine has been found to be highly elevated in patients infected with SARS-CoV-2. ${ }^{27} \mathrm{We}$ assessed the effect of TNF- $\alpha$ stimulation $(5 \mathrm{ng} / \mathrm{mL})$ on RUNX1 expression in HMEC-L primary cultures by immunofluorescence, RT-qPCR, and Western blot analysis. TNF- $\alpha$ stimulation alone increased RUNX1 staining compared with controls, whereas RUNX1 staining did not change on exposure to TGF- $\beta 1$ (Figure $3 \mathrm{H}$ ). A time course experiment demonstrated that RUNX1 mRNA increased by 2 -fold at 48 and 72 hours after TNF- $\alpha$ stimulation (Figure 3I). Ro24-7429 treatment $(75 \mu \mathrm{mol} / \mathrm{L})$ significantly reduced TNF- $\alpha$-induced up-regulation of RUNXI mRNA by 50\% (Figure 3J) at 48 hours. Similarly, treatment with another RUNX1 inhibitor, AI-14-91 $(1 \mu \mathrm{mol} /$ L), ${ }^{26}$ blunted TNF- $\alpha$-induced up-regulation of $R U N X 1$ mRNA by $50 \%$ at 48 hours (Figure 3J). These data demonstrate an inflammatory cytokine-linked mechanism in lung endothelial cells, which potentially explains the robust impact of RUNX1 inhibition on the inflammatory phase of bleomycin-induced lung injury via regulation of vascular endothelial cell function.

\section{RUNX1 Expression in COVID-19 Lung Tissue and Modulation of Critical SARS-CoV-2 Uptake Proteins by RUNX1}

We examined RUNX1 expression in seven postmortem lung tissue from patients, aged 59 to 84 years, deceased from COVID-19 and one control patient by immunohistochemistry. We found abnormal distribution of RUNX1 expression in a subset of SARS-CoV-2 virus infected lungs from two of seven deceased cases, localized to vessel endothelia and small capillaries. Five of seven cases presented with fibrosis and diffuse alveolar damage. Localized RUNX1 signal was not associated with pathologic presentation, although one RUNX1-positive case presented with viral load in formalin-fixed, paraffin-embedded lung tissue (Figure 4A, Supplemental Figures S3 and S4, and Supplemental Table S1). Overall, these findings highlight the possibility that RUNX1 might be a novel target to ameliorate lung pathology in severe COVID-19.

We further evaluated a potential functional link between RUNX1 function and the expression of ACE2 receptor and FURIN, a proprotein convertase, which are critical for SARS-CoV-2 virus uptake within host cells using our bleomycin-induced lung injury model and TGF- $\beta / T N F-$ $\alpha$-stimulated lung epithelial and vascular endothelial cells in vitro.

Immunofluorescence analysis of the 2-week time point in the bleomycin mouse model showed ACE2 expression localized to the areas with increased $\alpha$-SMA staining and fibrosis. Ro24-7429 treatment markedly reduced ACE2 staining and fibrosis in the lung (Figure 4B). In addition, we studied the effect of RUNX1 inhibition on the expression of ACE2 expression in TGF- $\beta 1-$ and TNF- $\alpha$-stimulated human-derived pulmonary alveolar epithelial cells. We found that TGF- $\beta 1$ and TNF- $\alpha$ exposure triggered upregulation of ACE2 protein levels (Figure $4, \mathrm{C}$ and D). RUNX1 inhibition significantly reduced TGF- $\beta 1-$ and TNF- $\alpha$-induced ACE2 protein levels in human-derived pulmonary alveolar epithelial cells. FURIN protein levels were also observed to go down by $70 \%$ in the Ro247429-treated mice, as evaluated by Western blot analysis (Figure 4, E and F).

\footnotetext{
Figure 2 Antifibrotic and anti-inflammatory effect of Ro24-7429 at day 7 in the bleomycin model of idiopathic pulmonary fibrosis. A and B: Histologic images and collagen deposition of the lung tissue were assessed by hematoxylin and eosin (H\&E) and Masson trichrome staining and visualized using brightfield microscopy. Boxed areas indicate areas magnified below. C: Representative transmission electron microscopy (TEM) micrographs at low magnification (top panels) and high magnification (bottom panels) of bleomycin- and Ro24-7429-treated lungs on day 14. Dotted boxed areas indicate areas magnified below. D and E: Detection of fibronectin, E-cadherin, and RUNX1 levels by Western blot analysis in bleomycin- and Ro24-7429-treated lungs. F: Quantitative PCR analysis of mRNA levels of fibronectin, collagen 3A1, RUNX1, and $\alpha$-SMA in bleomycin- and Ro24-7429-treated lungs. $\mathbf{G}$ and $\mathbf{H}$ : Immunohistochemistry on paraffin sections for $\alpha$-smooth muscle actin ( $\alpha$-SMA), RUNX1, IBA1, IB4, and LY6G. I: Quantification of IB4-, IBA1-, and LY6G-positive cells in bleomycin- and Ro24-7429-treated lungs. All data are presented as means \pm SEM (E, F, and I). $N=3$ bleomycin- and Ro24-7429-treated lungs $(\mathbf{D}$ and $\mathbf{E}) ; N=6$ bleomycinand Ro24-7429-treated lungs (F). ${ }^{*} P<0.05,{ }^{*} * P<0.01$, and ${ }^{* * * * P}<0.0001$. Scale bars: $50 \mu \mathrm{m}(\mathbf{A}) ; 1000 \mu \mathrm{m}(\mathbf{B}) ; 2 \mu \mathrm{m}$ (C, top panels); $500 \mu \mathrm{m}(\mathbf{C}$, bottom panels); $100 \mu \mathrm{m}$ (G and $\mathbf{H})$.
} 

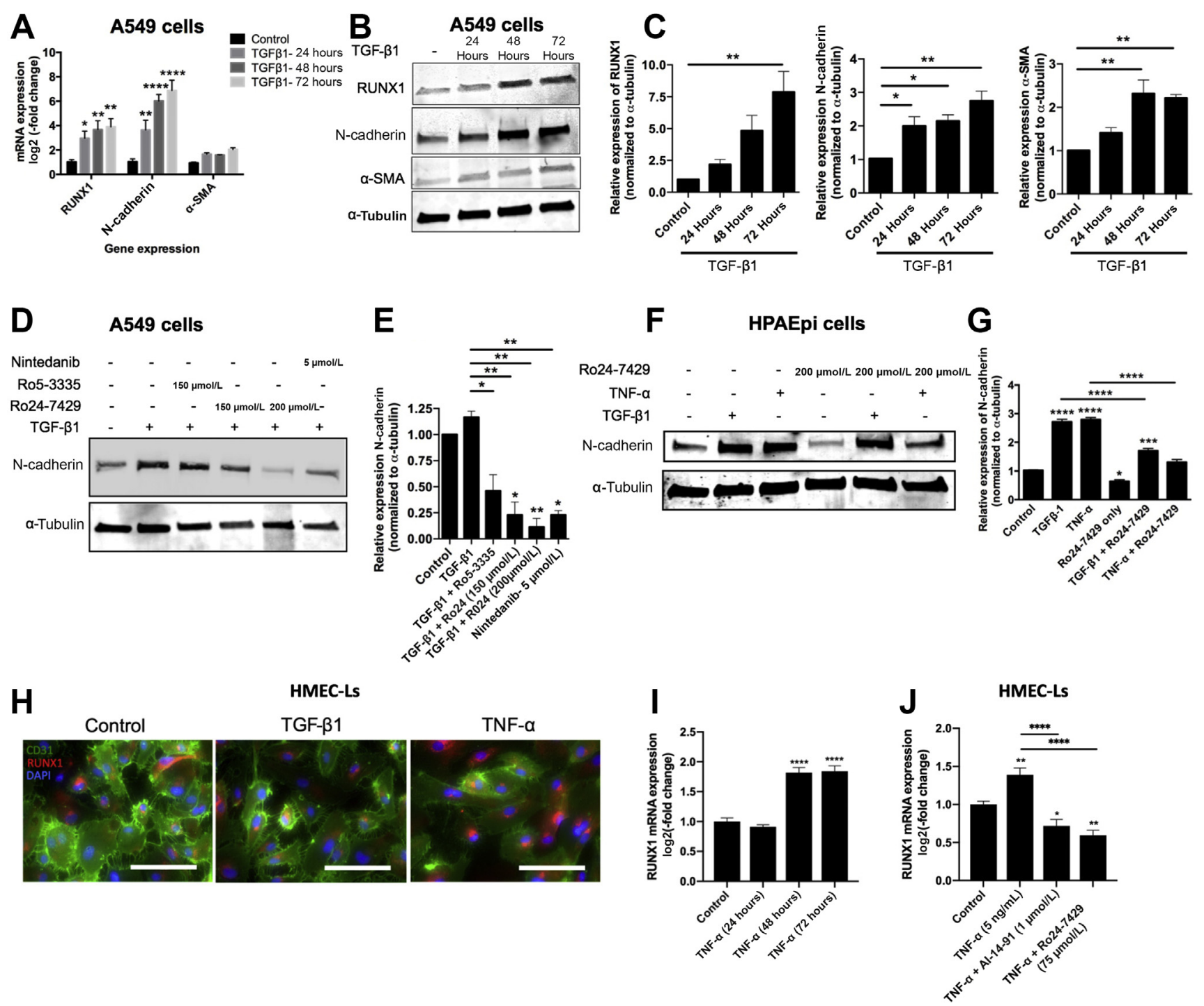

Figure 3 The effect of cytokine stimulation and Ro24-7429 treatment on expression of fibrosis markers in lung epithelial and vascular endothelial cells. A: Quantitative RT-PCR (RT-qPCR) analysis of mRNA levels of RUNX1, N-cadherin, and $\alpha$-SMA after 24, 48, and 72 hours of incubation with transforming growth factor (TGF)- $\beta 1$ in A549 cells. B: Western blot analysis of RUNX1, N-cadherin, and $\alpha$-smooth muscle actin ( $\alpha$-SMA) at 24,48 , and 72 hours of treatment with TGF- $\beta 1$ in A459 cells. C: Quantification of Western blot analysis for TGF- $\beta 1$ time course in A549 cells. D and E: Western blot analysis showing effect of Ro247429 on fibrotic marker N-cadherin after 72 hours of treatment with TGF- $\beta 1$ in A459 cells. $\mathbf{F}$ and $\mathbf{G}$ : Western blot analysis of fibrotic marker N-cadherin in human pulmonary alveolar epithelial (HPAEpi) cells stimulated with TGF- $\beta 1$ or tumor necrosis factor (TNF)- $\alpha$ with and without Ro24-7429 pretreatment. H: Representative images for human microvascular endothelial cells (lung; HMEC-Ls) fluorescently labeled with CD31 (green), RUNX1 (red), and DAPI (blue). I: RTqPCR analysis of mRNA levels of RUNX1 after 24, 48, and 72 hours of treatment with TNF- $\alpha$ in HMEC-Ls. J: RT-qPCR of $R U N X 1$ expression after pretreatment with AI-14-91 and Ro24-7429 with TNF- $\alpha$ treatment. All data are presented as means \pm SEM $(\mathbf{A}, \mathbf{C}, \mathbf{E}, \mathbf{G}, \mathbf{I}$, and $\mathbf{J}) . n=3(\mathbf{A}, \mathbf{C}, \mathbf{E}, \mathbf{G}, \mathbf{I}$, and $\mathbf{J}) .{ }^{*} P<0.05$, ${ }^{* * P}<0.01,{ }^{* * *} P<0.001$, and ${ }^{* * * * P}<0.0001$. Scale bar $=100 \mu \mathrm{m}(\mathbf{H})$.

We stimulated HMEC-Ls with TNF- $\alpha(5 \mathrm{ng} / \mathrm{mL})$ to further examine the link between RUNX1 function and FURIN expression using qPCR analysis. Ro24-7429 significantly reduced FURIN mRNA expression by $70 \%$ (Figure 4G), whereas AI-14-91 reduced mRNA expression by $50 \%$. In addition, RUNX1 stimulation via TNF- $\alpha$ and inhibition using AI-14-91 and Ro24-7429 demonstrated significant effects on the expression of TNF-R1 mRNA. A significant $60 \%$ decrease was seen in TNF-R1 expression when cells were stimulated with TNF- $\alpha$ in the presence of Ro24-7429. A smaller, but significant, reduction of $40 \%$ was seen in $T N F-R 1$ levels when AI-1491 was used to inhibit RUNX1 (Figure 4I). In addition, in the mouse model of bleomycin, the day 14 time point showed significant reduction in TNF-RI mRNA expression after treatment with Ro24-7429. This led us to the conclusion that RUNX1 inhibition reduces not only ACE2 and FURIN in the mouse model and in vitro, but also expression of tumor necrosis factor receptor 1 (TNF-R1) (Figure 4H). Because RUNX1 inhibition blunts the 


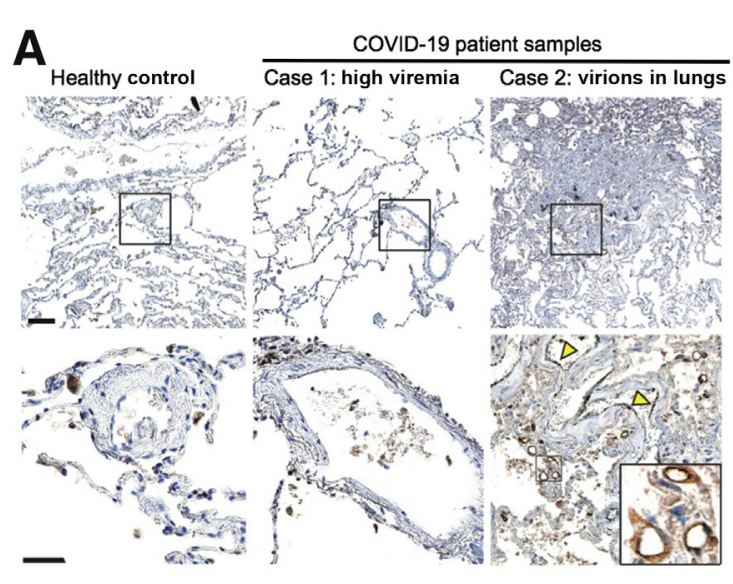

D

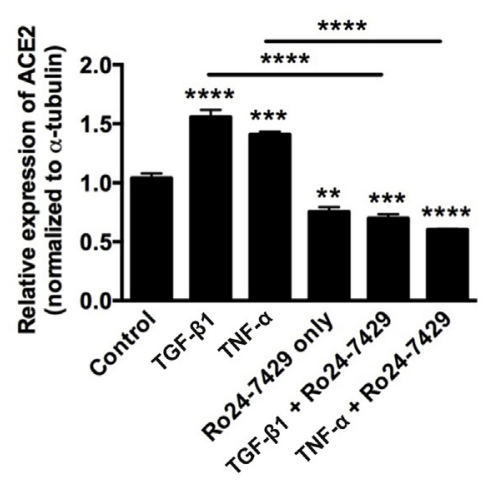

G

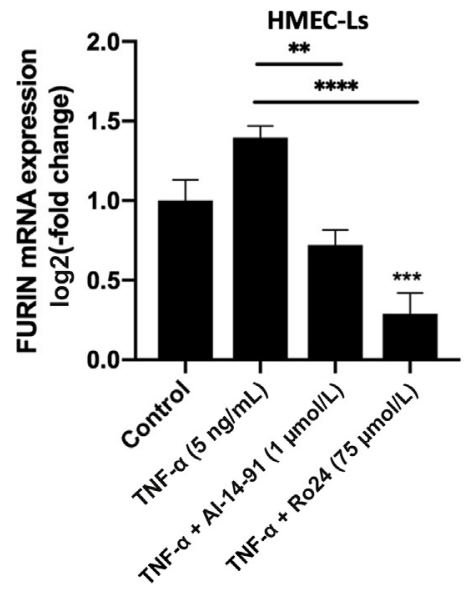

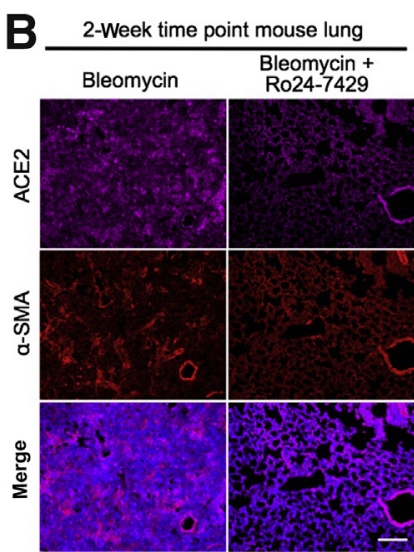

E

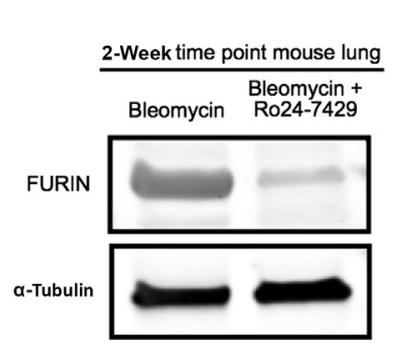

H

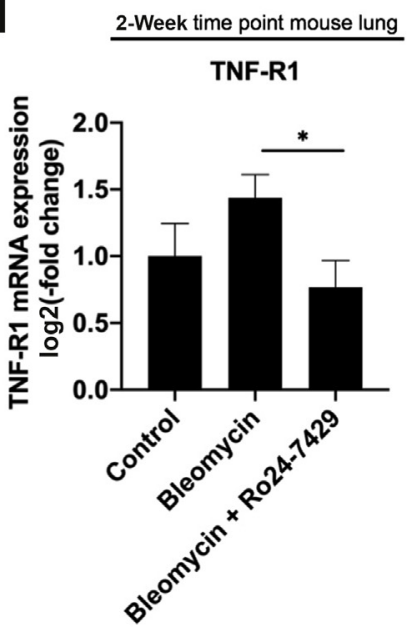

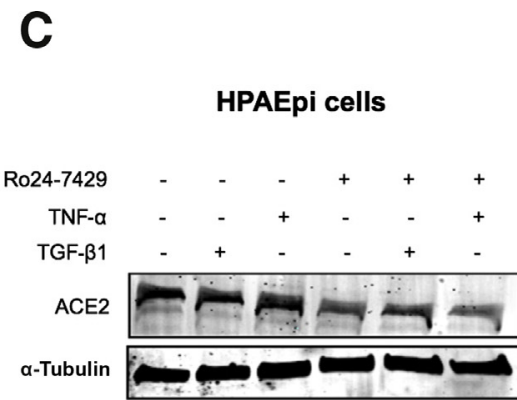

$\mathbf{F}$

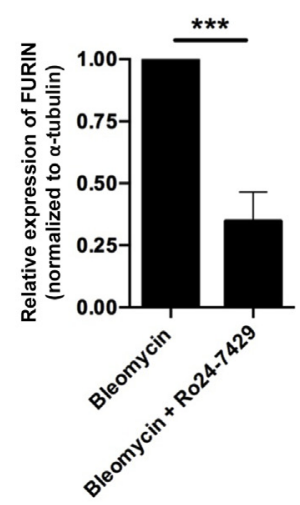

I

HMEC-LS

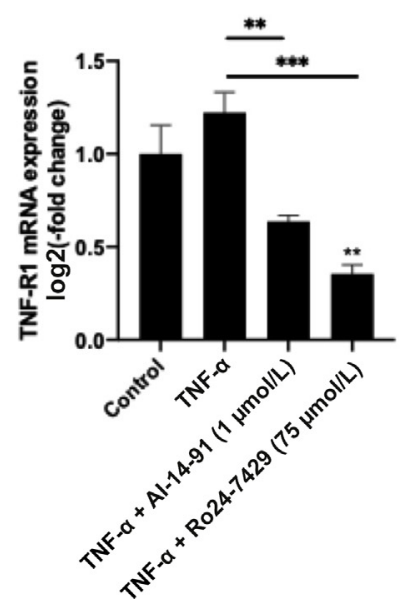

Figure 4 RUNX1 expression during SARS-CoV-2 infection and the in vitro and in vivo effects of RUNX1 inhibition in human epithelial and endothelial cells. A: RUNX1 expression in human control lungs and two cases with SARS-CoV-2 with low (case 1) or high abundance of viral proteins in lung (cases 2) by immunostaining. Only case 2 shows RUNX1 signal in endothelia (yellow triangles) and capillaries (inset). B: Angiotensin-converting enzyme 2 (ACE2) $\alpha$ smooth muscle actin ( $\alpha$-SMA) immunostaining at the 2-week time point. C and D: Western blot analysis showing transforming growth factor (TGF)- $\beta 1$ and tumor necrosis factor (TNF)- $\alpha$ induction of ACE2 with or without Ro24-7429 pretreatment. E and F: Western blot analysis showing FURIN expression in bleomycin- and Ro24-7429-treated lungs. G: Quantitative RT-PCR (RT-qPCR) analysis of mRNA of FURIN after pretreatment with AI-14-91 or Ro24-7429 in the presence of TNF- $\alpha$ or in human microvascular endothelial cells (lung; HMEC-Ls). H: RT-qPCR analysis of mRNA of TNF-R1 in bleomycin- and Ro24-7429-treated lungs. I: RT-qPCR analysis of mRNA of TNF-R1 after pretreatment with AI-14-91 or Ro24-7429. All data are presented as means \pm SEM (D, F, and G-I). N $=5$ $(\mathbf{F}) ; n=5$ to 6 (D, G-I). ${ }^{*} P<0.05,{ }^{* *} P<0.01,{ }^{* * *} P<0.001$, and ${ }^{* * * *} P<0.0001$. Scale bar $=100 \mu \mathrm{m}(\mathbf{A}$ and $\mathbf{B})$. HPAEpi, human pulmonary alveolar epithelial; TNFR1, tumor necrosis factor receptor 1 .

expression of ACE2 and FURIN in a mouse model of lung injury and in human epithelial and vascular endothelial cells in vitro, this modality of treatment may have a role for the treatment of COVID-19 (Figure 4I).
Relative changes in expression of angiogenesisassociated genes have been identified by others in the lungs of COVID-19 patients. ${ }^{16}$ Of the 113 reported genes, 100 were seen to have a relative increase in gene 


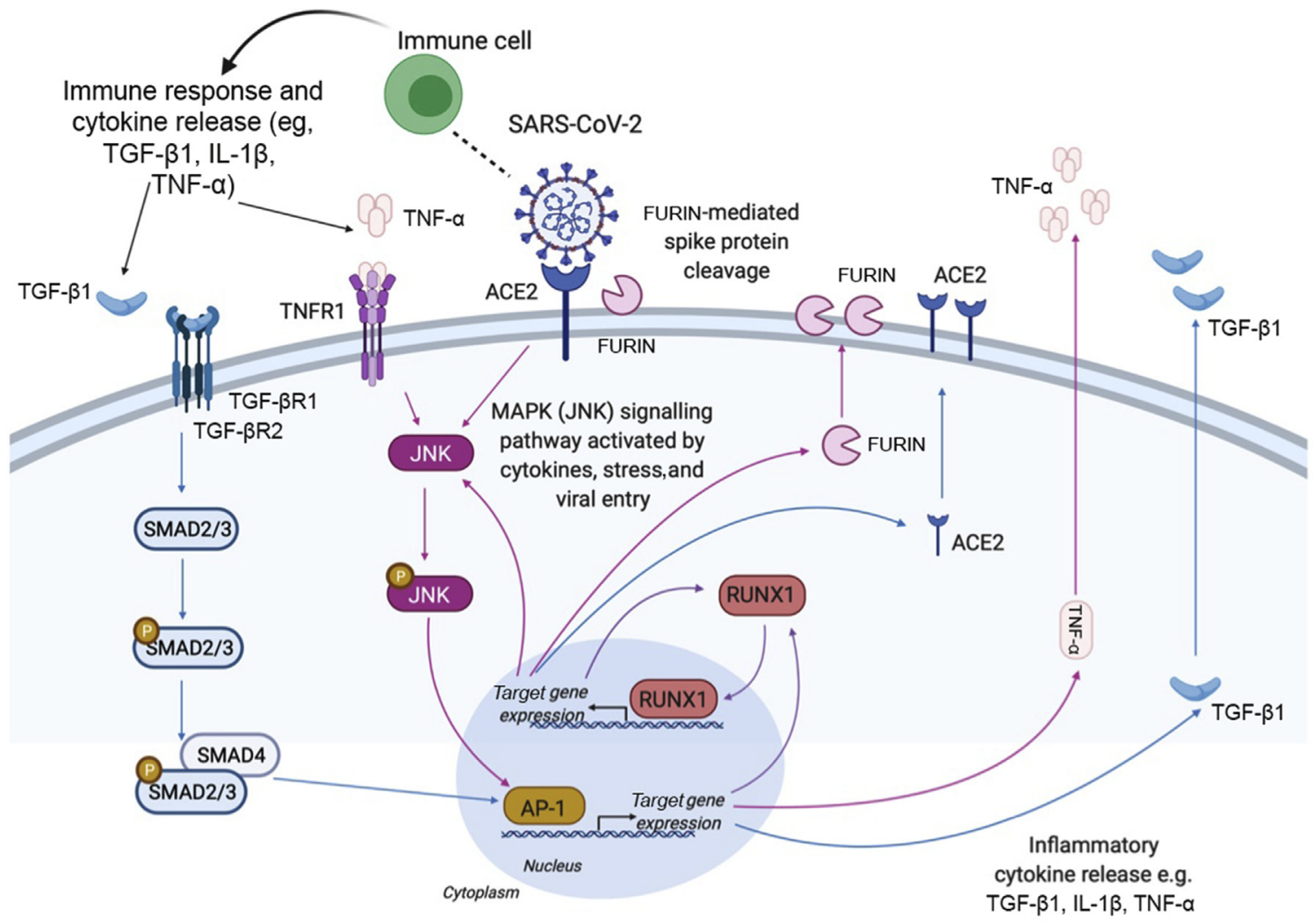

Figure 5 Schematic of hypothesis of RUNX1's role in transforming growth factor (TGF)- $\beta 1$ (blue), tumor necrosis factor (TNF)- $\alpha$ (pink), and shared (purple) signaling and its effects on SARS-CoV-2-related proteins FURIN and angiotensin-converting enzyme 2 (ACE2). JNK, c-Jun N-terminal kinase; MAPK, mitogenactivated protein kinase.

expression in COVID-19 patients compared with controls. We used oPOSSUM software to map RUNX1 or AP-1 (previously shown to drive RUNX1 expression in endothelial cells) TFBS profiles in these 113 genes (Supplemental Figure S5). Of these, 88 genes (78\%) were target gene hits for RUNX1 (Z-score, 15.370; Fisher score, 11.682), meaning they share conserved TFBSs, and 98 genes (87\%) were target gene hits for AP-1 (Z-score, 14.568; Fisher score, 12.297). Manual analysis of the TFBSs demonstrated an overlap of 85 genes, which contain both AP-1 and RUNX1 TFBSs, as well as 17 genes that are strongly associated with the JNK signaling pathway. Only 12 of 113 COVID-19 genes showed no target gene hits against an AP-1 or RUNX1 JASPAR CORE profile (Supplemental Figures S5 and S6). These data support the importance of RUNX1, as well as the JNK-AP-1-RUNX1 pathway (Figure 5), in the regulation of angiogenesis-associated genes, which are upregulated in a severe COVID-19 disease state that ultimately leads to patient deaths in many cases.

\section{Discussion}

To our knowledge, this is the first study to demonstrate the preclinical efficacy of the small molecule Ro24-7429 and RUNX1 inhibition in the bleomycin model of PF. The Ro24-7429 dose used herein is equivalent to dosages previously tested in phase $1 / 2$ trials that had a strong safety profile. ${ }^{31}$ We report that pretreatment with Ro24-7429 significantly reduces fibrosis and maintains alveolar structure through the inhibition of RUNX1 activity.

TGF- $\beta 1$ is a critical mediator of pulmonary fibrosis, and its expression is augmented in animal models of lung fibrosis and in human lungs with IPF. ${ }^{38,40}$ TGF- $\beta 1$ is involved in a range of cellular changes, including proliferation, differentiation, apoptosis, and death. ${ }^{41}$ TGF- $\beta 1$ activation induces extracellular matrix production, and its effects are mediated through the SMAD2/3 pathway, as illustrated through SMAD3 knockout that was found to prevent fibrosis in the bleomycin mouse model. ${ }^{42}$ Recent publications have highlighted the role of TGF- $\beta 1 /$ SMAD/ RUNX1 signaling in IPF. ${ }^{3}$ There has been growing interest in the role of RUNX1 inhibition in preventing fibrosis in various organ systems, including renal tubular epithelial cells, in which RUNX1 was found to regulate markers of epithelial-to-mesenchymal transition and knockout of RUNX1 prevented kidney fibrosis. ${ }^{43}$ In addition, RUNX1 has been suggested to have an important role in fibroblast activation and proliferation. ${ }^{44}$ RUNX1 is highly expressed in lipofibroblasts that are believed to be a source of 
myofibroblasts that contribute to IPF. ${ }^{45}$ Activation of fibroblasts and myofibroblasts results in an excessive deposition of extracellular matrix proteins, an important pathogenic event that impairs lung function. ${ }^{46}$

The mechanism of how SARS-CoV-2 leads to pulmonary fibrosis is yet to be determined. However, it is known that viral infection is a risk factor for pulmonary fibrosis. ${ }^{47}$ TNF$\alpha$ has been implicated during respiratory virus infections and accelerates the development of pulmonary fibrosis. ${ }^{48}$ TNF- $\alpha$ can act as an amplifier of inflammation and has an important role in a range of acute inflammatory reactions. ${ }^{49}$ TNF- $\alpha$ is considered to be pro-angiogenic in vivo, and elevated levels of TNF- $\alpha$ are implicated in several respiratory diseases, including asthma, chronic obstructive pulmonary disorder, and acute respiratory distress syndrome. ${ }^{50-53}$ More important, TNF- $\alpha$ expression directly is correlated with increased endothelial permeability. ${ }^{54} \mathrm{In}$ endothelial cells, TNF- $\alpha$ signals to RUNX1 through a JNK pathway feedback loop. ${ }^{27}$ Specifically, in the lung, inhibition of TNF- $\alpha$ signaling has been shown to reduce collagen deposition, and additionally regulate the expression of the profibrotic mediator TGF- $\beta 1 .^{39,52}$

Current drugs with antifibrotic activity, such as nintedanib and pirfenidone, have been found to slow IPF progress. ${ }^{4}$ Our data indicate that RUNX1 inhibition may operate via multiple pathways, impacting different stages of PF progression. We have demonstrated in vitro and in vivo that RUNX1 inhibition prevents pathologic changes in the presence of TGF- $\beta 1$ and TNF- $\alpha$ in human alveolar epithelial cells and human vascular endothelial cells, respectively. Cytokine signaling, caused by immune cell activation, cellular damage, and inflammation, activates downstream pathways, including the JNK pathway in endothelial cells and the SMAD pathway in lung epithelial cells. $^{27,55,56}$ Both the JNK and SMAD pathways converge on AP-1, as each is capable of activating/phosphorylating c-Jun, which dimerizes with c-Fos to form AP-1. AP-1 is known to cause the further production of inflammatory cytokines and is also linked to RUNX1 expression (Figure $4 \mathrm{H}$ ). ${ }^{27,57}$ These data clarify the role of cytokine signaling in mediating convergent RUNX1 activity in the bleomycin-induced model of IPF.

Previous studies evaluating the role of RUNX1 in lung epithelium have shown increased RUNX1 expression in lung tissue in response to acute lung injury via lipopolysaccharide exposure. ${ }^{58}$ Thus, it seems that elevated RUNX1 expression is a common response to lung injury. Conditional knockout of RUNX1 within the lung epithelium increased susceptibility of acute lung injury to lipopolysaccharide via activation of NF- $\kappa \mathrm{B} .{ }^{59}$ Our work shows that pharmacologic inhibition of RUNX1 inhibition via Ro247429 inhibits inflammation in adult tissues, suggesting that pharmacologic inhibition may allow for normal baseline RUNX1 activity, while inhibiting aberrant activity of RUNX1. It is also possible that the developmental transcriptional targets of RUNX1 may be different from the transcriptional targets in adult tissues. Furthermore, we inhibit RUNX1 systemically, allowing for inhibition within multiple cell types beyond epithelium, including fibroblasts, vascular endothelium, and inflammatory cells.

A potential limitation of the study is that we cannot rule out additional effects beyond RUNX1 inhibition of Ro247429 as it has also been investigated as a Tat antagonist. ${ }^{30,31}$ However, to validate the effects of RUNX1 inhibition in vitro, we used AI-14-91, a validated RUNX1 inhibitor, in the HMEC-Ls. In addition, we have shown that Ro24-7429 causes a reduction in fibrotic makers, a phenotype also reported in studies that inhibited RUNX1 through molecular approaches. ${ }^{3}$ We report that RUNX1 localization and signal is increased in a subset of human lungs infected with SARS$\mathrm{CoV}-2$. This finding needs to be explored further in a larger sample once our understanding of COVID-19 pathobiology increases. Interestingly, RUNX1 has recently been predicted to modulate ACE2 and FURIN expression based on genomic-guided molecular maps of upstream regulatory elements. ${ }^{33}$ We report for the first time that RUNX1 expression directly correlates with ACE2 and FURIN expression levels both in vitro and in vivo.

FURIN is a ubiquitous proprotein convertase involved in the proteolytic processing of a wide range of precursor proteins and activates several factors that are believed to be important in IPF, including TGF- $\beta 1$, a major contributing factor to the fibrotic changes associated with IPF. Initially, TGF- $\beta 1$ is produced as an inactive polypeptide that requires correct proteolytic cleavage for its activation. The TGF- $\beta 1$ cleavage site consists of an R-H-R-R sequence similar to the proprotein convertase recognition motifs. Interestingly, this cleavage site is correctly cleaved by FURIN, a member of the proprotein convertase family. ${ }^{60,61}$ However, TGF- $\beta 1$ is also cleaved by several other factors, including integrin $\alpha v \beta 6$ and the serine protease plasmin. ${ }^{38}$ FURIN is also known to activate matrix metalloproteinase 28. Matrix metalloproteinase 28 is known to promote $\mathrm{PF}$ in bleomycintreated mice by inducing macrophages to change from the classically activated (M1) phenotype to an alternatively activated (M2) phenotype that has an important impact on collagen deposition. ${ }^{62}$ Moreover, this observation warrants the investigation of Ro24-7429 as a potential therapeutic target in the battle with SARS-CoV-2 as this may have multiple avenues of efficacy as we and others have identified RUNX1 up-regulation in lung tissue from postmortem lungs of COVID-19 patients. ${ }^{16}$ FURIN is a critical enzyme involved in the cleavage of the spike protein $\mathrm{S} 1 / \mathrm{S} 2$ to allow subsequent interaction with ACE2 and viral internalization, and more important, Ro24-7429 could have the potential to prevent postinfection associated fibrosis.

In conclusion, these data indicate that RUNX1 is involved in multiple steps of the pathobiology of pulmonary fibrosis, and RUNX1 inhibition may lead to an effective new therapy for PF of multiple etiologies. Our data suggest that RUNX1 transcriptional activity likely plays a critical role in the pathologic host response to SARS-CoV-2 infection, regulating the epithelial, fibroblast, and endothelial cell response. Our oPOSSUM analysis of TFBSs in 
genes found to be dysregulated in patients with COVID-19 revealed that $78 \%$ of these genes contain RUNX1 TFBSs, suggesting that RUNX1 has an important role in the pathobiology of COVID-19. ${ }^{16}$ We surmise that repurposing of Ro24-7429 for the treatment of PF in patients with or without COVID-19 should be examined in clinical trials. Ro24-7429 was tested in a phase 2 clinical trial in patients with HIV. Ro24-7429 did not have sufficient antiviral activity but was found to be safe at doses $\leq 300 \mathrm{mg} /$ day orally. A rash that appeared in a dose-dependent manner and recovered shortly after withdrawal was the only major adverse effect after 12 weeks of treatment. Because Ro247429 was already used in immunocompromised patients, it is likely to be safe to test in COVID-19 patients as means to prevent or treat life-threatening complications.

\section{Data and Materials Availability}

Clinical and imaging data are available on request, subject to an internal review by L.A.K., J.F.A.-V., and D.S.-F. to ensure that the participants' anonymity and confidentiality are protected. Experimental data are available on request. Material requests and data requests will be considered on the basis of a proposal review, completion of a material transfer agreement and/or a data use agreement, and in accordance with the Schepens Eye Research Institute of Mass Eye and Ear institutional guidelines. Please submit requests for data to L.A.K. (leo_kim@ @meei.harvard.edu) or J.F.A.-V.

\section{Acknowledgments}

We thank Candace Beiler and members of the Schepens Eye Research Institute Institutional Animal Care and Use Committee and Maria Ortega, Erica Tolley, and Miele Macmillan from Schepens Eye Research Institute's animal facility for assistance with this project during the coronavirus disease 2019 (COVID-19) shutdown; members of the Schepens Eye Research Institute morphology core, including Philip Seifert and Bianai Fan, for assistance with this project; Kristin Hartmann from University Medical Center Hamburg for technical assistance; and Andrew Firger for assistance and encouragement to make this work possible. H.A.B.W. would like to personally thank the Consular Information Unit and the Nonimmigrant Visa Unit at the US Embassy in London, UK, for assistance in obtaining a National Interest Exemption Waiver to allow her return to the United States during the COVID-19 pandemic to work on this project.

\section{Author contributions}

J.F.A.-V. and L.A.K. initiated this work and supervised all the aspects of the project. L.A.K., J.F.A.-V., M.O.H., D.A., and D.S.-F. designed the experiments. M.O.H., D.A., and
H.A.B.W. conducted and analyzed experiments. J.F.A.-V. performed intratracheal instillation procedures. M.A., L.R., H.A.B.W., C.M., S.D.T., and X.H. provided assistance for the experiments. N.C. and A.C. provided assistance with data analysis. A.F., S.S., S.K., B.O., M.G., and D.S.-F. studied severe acute respiratory syndrome coronavirus 2 human lung samples. M.O.H. and D.A. wrote the manuscript. H.A.B.W. and D.S.-F. assisted in drafting the manuscript. L.A.K. and J.F.A.-V. are the guarantors of this work and, as such, had full access to all the data in the study and take responsibility for the integrity of the data and the accuracy of the data analysis.

\section{Supplemental Data}

Supplemental material for this article can be found at http://doi.org/10.1016/j.ajpath.2021.04.006.

\section{References}

1. Lederer DJ, Martinez FJ: Idiopathic pulmonary fibrosis. N Engl J Med 2018, 378:1811-1823

2. Selman M, Pardo A: Idiopathic pulmonary fibrosis: an epithelial/fibroblastic cross-talk disorder. Respir Res 2002, 3:3

3. Lin S, Zhang R, Xu L, Ma R, Xu L, Zhu L, Hu J, An H: LncRNA Hoxaas 3 promotes lung fibroblast activation and fibrosis by targeting miR-450b-5p to regulate Runx1. Cell Death Dis 2020, 11:706

4. Graney BA, Lee JS: Impact of novel antifibrotic therapy on patient outcomes in idiopathic pulmonary fibrosis: patient selection and perspectives. Patient Relat Outcome Meas 2018, 9:321-328

5. Maher TM: PROFILEing idiopathic pulmonary fibrosis: rethinking biomarker discovery. Eur Respir Rev 2013, 22:148

6. Vancheri C, Kreuter M, Richeldi L, Ryerson CJ, Valeyre D, Grutters JC, Wiebe S, Stansen W, Quaresma M, Stowasser S, Wuyts WA: Nintedanib with add-on pirfenidone in idiopathic pulmonary fibrosis: results of the INJOURNEY Trial. Am J Respir Crit Care Med 2018, 197:356-363

7. Hutchinson J, Fogarty A, Hubbard R, McKeever T: Global incidence and mortality of idiopathic pulmonary fibrosis: a systematic review. Eur Respir J 2015, 46:795

8. Strongman H, Kausar I, Maher TM: Incidence, prevalence, and survival of patients with idiopathic pulmonary fibrosis in the UK. Adv Ther 2018, 35:724-736

9. Gallay L, Uzunhan Y, Borie R, Lazor R, Rigaud P, MarchandAdam S, Hirschi S, Israel-Biet D, Valentin V, Cottin V: Risk factors for mortality after COVID-19 in patients with preexisting interstitial lung disease. Am J Respir Crit Care Med 2021, 203:245-249

10. Ojo AS, Balogun SA, Williams OT, Ojo OS: Pulmonary fibrosis in COVID-19 survivors: predictive factors and risk reduction strategies. Pulm Med 2020, 2020:6175964

11. George PM, Wells AU, Jenkins RG: Pulmonary fibrosis and COVID19: the potential role for antifibrotic therapy. Lancet Respir Med 2020, 8:807-815

12. Eapen MS, Lu W, Gaikwad AV, Bhattarai P, Chia C, Hardikar A, Haug G, Sohal SS: Endothelial to mesenchymal transition: a precursor to post-COVID-19 interstitial pulmonary fibrosis and vascular obliteration? Eur Respir J 2020, 56:2003167

13. Huertas A, Montani D, Savale L, Pichon J, Tu L, Parent F Guignabert C, Humbert M: Endothelial cell dysfunction: a major player in SARS-CoV-2 infection (COVID-19)? Eur Respir J 2020, $56: 2001634$ 
14. Martines RB, Ritter JM, Matkovic E, Gary J, Bollweg BC, Bullock H, Goldsmith CS, Silva-Flannery L, Seixas JN, ReaganSteiner S, Uyeki T, Denison A, Bhatnagar J, Shieh W-J, Zaki SR: Pathology and pathogenesis of SARS-CoV-2 associated with fatal coronavirus disease, United States. Emerg Infect Dis 2020, 26: 2005-2015

15. Schaefer I-M, Padera RF, Solomon IH, Kanjilal S, Hammer MM, Hornick JL, Sholl LM: In situ detection of SARS-CoV-2 in lungs and airways of patients with COVID-19. Mod Pathol 2020, 33: 2104-2114

16. Ackermann M, Verleden SE, Kuehnel M, Haverich A, Welte T, Laenger F, Vanstapel A, Werlein C, Stark H, Tzankov A, Li WW, Li VW, Mentzer SJ, Jonigk D: Pulmonary vascular endothelialitis, thrombosis, and angiogenesis in Covid-19. N Engl J Med 2020, 383: $120-128$

17. Polak SB, Van Gool IC, Cohen D, von der Thüsen JH, van Paassen J: A systematic review of pathological findings in COVID-19: a pathophysiological timeline and possible mechanisms of disease progression. Mod Pathol 2020, 33:2128-2138

18. Gibson PG, Qin L, Puah SH: COVID-19 acute respiratory distress syndrome (ARDS): clinical features and differences from typical preCOVID-19 ARDS. Med J Aust 2020, 213:54-56.e1

19. Rai DK, Sharma P, Kumar R: Post covid 19 pulmonary fibrosis- is it reversible? Indian J Tuberc 2020, [Epub ahead of print] doi: 10.1016/ j.ijtb.2020.11.003

20. Beigel JH, Tomashek KM, Dodd LE, Mehta AK, Zingman BS, Kalil AC, et al: Remdesivir for the treatment of Covid-19 - final report. N Engl J Med 2020, 383:1813-1826

21. Group RC: Dexamethasone in hospitalized patients with Covid-19preliminary report. N Engl J Med 2021, 387:693-704

22. Pashaei M, Rezaei N: Immunotherapy for SARS-CoV-2: potential opportunities. Expert Opin Biol Ther 2020, 20:1111-1116

23. Yzaguirre AD, de Bruijn MFTR, Speck NA: The role of Runx1 in embryonic blood cell formation. Edited by Groner Y, Ito Y, Liu P, Neil JC, Speck NA, van Wijnen A. In RUNX Proteins in Development and Cancer. Singapore: Springer Singapore, 2017. pp. 47-64

24. Bravo J, Li Z, Speck NA, Warren AJ: The leukemia-associated AML1 (Runx1)-CBFß complex functions as a DNA-induced molecular clamp. Nat Struct Bio 2001, 8:371-378

25. Cunningham L, Finckbeiner S, Hyde RK, Southall N, Marugan J, Yedavalli VRK, Dehdashti SJ, Reinhold WC, Alemu L, Zhao L, Yeh JR, Sood R, Pommier Y, Austin CP, Jeang KT, Zheng W, Liu P: Identification of benzodiazepine Ro5-3335 as an inhibitor of CBF leukemia through quantitative high throughput screen against RUNX1-CBF $\beta$ interaction. Proc Natl Acad Sci U S A 2012, 109: 14592

26. Illendula A, Gilmour J, Grembecka J, Tirumala VSS, Boulton A, Kuntimaddi A, Schmidt C, Wang L, Pulikkan JA, Zong H, Parlak M, Kuscu C, Pickin A, Zhou Y, Gao Y, Mishra L, Adli M, Castilla LH, Rajewski RA, Janes KA, Guzman ML, Bonifer C, Bushweller JH: Small molecule inhibitor of CBF $\beta$ RUNX binding for RUNX transcription factor driven cancers. EBioMedicine 2016, 8:117-131

27. Whitmore HAB, Amarnani D, O'Hare M, Delgado-Tirado S, Gonzalez-Buendia L, An M, Pedron J, Bushweller JH, ArboledaVelasquez JF, Kim LA: TNF- $\alpha$ signaling regulates RUNX1 function in endothelial cells. FASEB 2021, 35:e21155

28. Lam JD, Oh DJ, Wong LL, Amarnani D, Park-Windhol C, Sanchez AV, Cardona-Velez J, McGuone D, StemmerRachamimov AO, Eliott D, Bielenberg DR, van Zyl T, Shen L, Gai X, D'Amore PA, Kim LA, Arboleda-Velasquez JF: Identification of RUNX1 as a mediator of aberrant retinal angiogenesis. Diabetes 2017, 66:1950-1956

29. Delgado-Tirado S, Amarnani D, Zhao G, Rossin EJ, Eliott D, Miller JB, Greene WA, Ramos L, Arevalo-Alquichire S, LeytonCifuentes D, Gonzalez-Buendia L, Isaacs-Bernal D, Whitmore HAB, Chmielewska N, Duffy BV, Kim E, Wang HC, Ruiz-Moreno JM,
Kim LA, Arboleda-Velasquez JF: Topical delivery of a small molecule RUNX1 transcription factor inhibitor for the treatment of proliferative vitreoretinopathy. Sci Rep 2020, 10:20554

30. Hsu MC, Dhingra U, Earley JV, Holly M, Keith D, Nalin CM, Richou AR, Schutt AD, Tam SY, Potash MJ: Inhibition of type 1 human immunodeficiency virus replication by a tat antagonist to which the virus remains sensitive after prolonged exposure in vitro. Proc Natl Acad Sci U S A 1993, 90:6395-6399

31. Haubrich RH, Flexner C, Lederman MM, Hirsch M, Pettinelli CP, Ginsberg R, Lietman P, Hamzeh FM, Spector SA, Richman DD; The AIDS Clinical Trials Group 213 Team: A randomized trial of the activity and safety of Ro 24-7429 (Tat antagonist) versus nucleoside for human immunodeficiency virus infection. J Infect Dis 1995, 172: $1246-1252$

32. Tashiro J, Rubio GA, Limper AH, Williams K, Elliot SJ, Ninou I, Aidinis V, Tzouvelekis A, Glassberg MK: Exploring animal models that resemble idiopathic pulmonary fibrosis. Front Med 2017, 4:118

33. Glinsky GV: Tripartite combination of candidate pandemic mitigation agents: vitamin D, quercetin, and estradiol manifest properties of medicinal agents for targeted mitigation of the COVID-19 pandemic defined by genomics-guided tracing of SARS-CoV-2 targets in human cells. Biomedicines 2020, 8:129

34. Kremer S, Breuer R, Lossos IS, Berkman N, Christensen TG, Connor MW, Breuer R: Effect of immunomodulators on bleomycininduced lung injury. Respiration 1999, 66:455-462

35. Laxer U, Lossos IS, Gillis S, Or R, Christensen TG, Goldstein RH, Breuer R: The effect of enoxaparin on bleomycin-induced lung injury in mice. Exp Lung Res 1999, 25:531-541

36. Berkman N, Kremer S, Or R, Lossos IS, Christensen TG, Goldstein RH, Breuer R: Human recombinant interferon-alpha2a and interferon-alphaA/D have different effects on bleomycin-induced lung injury. Respiration 2001, 68:169-177

37. Edler C, Schröder AS, Apfelbacher M, Fitzek A, Heinemann A, Heinrich F, Klein A, Langenwalder F, Lutgehetmann M, Meissner K, Puschel K, Schadler J, Steurer S, Mushumba H, Sperhake J-P: Dying with SARS-CoV-2 infection-an autopsy study of the first consecutive 80 cases in Hamburg, Germany. Int J Legal Med 2020, 134 : $1275-1284$

38. Yue X, Shan B, Lasky JA: TGF- $\beta$ : titan of lung fibrogenesis. Curr Enzym Inhib 2010, 6. 10.2174/10067

39. Malaviya R, Laskin JD, Laskin DL: Anti-TNF $\alpha$ therapy in inflammatory lung diseases. Pharmacol Ther 2017, 180:90-98

40. Hoyt DG, Lazo JS: Alterations in pulmonary mRNA encoding procollagens, fibronectin and transforming growth factor-beta precede bleomycin-induced pulmonary fibrosis in mice. J Pharmacol Exp Ther 1988, 246:765-771

41. Lee J, Choi JH, Joo CK: TGF- $\beta 1$ regulates cell fate during epithelial-mesenchymal transition by upregulating survivin. Cell Death Dis 2013, 4:e714

42. Bonniaud P, Kolb M, Galt T, Robertson J, Robbins C, Stampfli M, Lavery C, Margetts PJ, Roberts AB, Gauldie J: Smad3 null mice develop airspace enlargement and are resistant to TGF- $\beta$-mediated pulmonary fibrosis. J Immunol 2004, 173:2099

43. Zhou T, Luo M, Cai W, Zhou S, Feng D, Xu C, Wang H: Runtrelated transcription factor 1 (RUNX1) promotes TGF- $\beta$-induced renal tubular epithelial-to-mesenchymal transition (EMT) and renal fibrosis through the PI3K subunit p1108. EBioMedicine 2018, 31: 217-225

44. Kim W, Kim W, Barron DA, San Martin R, Chan KS, Tran LL, Yang F, Ressler SJ, Rowley DR: RUNX1 is essential for mesenchymal stem cell proliferation and myofibroblast differentiation. Proc Natl Acad Sci U S A 2014, 111:16389-16394

45. Xie T, Wang Y, Deng N, Huang G, Taghavifar F, Geng Y, Liu N, Kulur V, Yao C, Chen P, Liu Z, Stripp B, Tang J, Liang J, Noble PW, Jiang D: Single-cell deconvolution of fibroblast heterogeneity in mouse pulmonary fibrosis. Cell Rep 2018, 22:3625-3640 
46. Frangogiannis NG: Fibroblast-extracellular matrix interactions in tissue fibrosis. Curr Pathobiol Rep 2016, 4:11-18

47. Sheng G, Chen P, Wei Y, Yue H, Chu J, Zhao J, Wang Y, Zhang W, Zhang H-L: Viral infection increases the risk of idiopathic pulmonary fibrosis: a meta-analysis. CHEST 2020, 157:1175-1187

48. Hou J, Shi J, Chen L, Lv Z, Chen X, Cao H, Xiang Z, Han X: M2 macrophages promote myofibroblast differentiation of LR-MSCs and are associated with pulmonary fibrogenesis. Cell Commun Signal 2018, 16:89

49. Del Valle DM, Kim-Schulze S, Huang H-H, Beckmann ND, Nirenberg S, Wang B, Lavin Y, Swartz TH, Madduri D, Stock A, Marron TU, Xie H, Patel M, Tuballes K, Van Oekelen O, Rahman A, Kovatch P, Aberg JA, Schadt E, Jagannath S, Mazumdar M, Charney AW, Firpo-Betancourt A, Mendu DR, Jhang J, Reich D, Sigel K, Cordon-Cardo C, Feldmann M, Parekh S, Merad M, Gnjatic S: An inflammatory cytokine signature predicts COVID-19 severity and survival. Nat Med 2020, 26:1636-1643

50. Sainson RC, Johnston DA, Chu HC, Holderfield MT, Nakatsu MN, Crampton SP, Davis J, ConnE, Hughes CC: TNF primes endothelial cells for angiogenic sprouting by inducing a tip cell phenotype. Blood 2008, 111:4997-5007

51. Fràter-Schröder M, Risau W, Hallmann R, Gautschi P, Böhlen P: Tumor necrosis factor type alpha, a potent inhibitor of endothelial cell growth in vitro, is angiogenic in vivo. Proc Natl Acad Sci U S A 1987, 84:5277-5281

52. Malaviya R, Sunil VR, Venosa A, Verissimo VL, Cervelli JA, Vayas KN, Hall L, Laskin JD, Laskin DL: Attenuation of nitrogen mustard-induced pulmonary injury and fibrosis by anti-tumor necrosis factor- $\alpha$ antibody. Toxicol Sci 2015, 148:71-88

53. Mukhopadhyay S, Hoidal JR, Mukherjee TK: Role of TNF $\alpha$ in pulmonary pathophysiology. Respir Res 2006, 7:125
54. Sinha P, Ware LB: Selective tumour necrosis factor receptor-1 inhibition in acute lung injury: a new hope or a false dawn? Thorax 2018 , 73:699

55. Liberati NT, Datto MB, Frederick JP, Shen X, Wong C, RougierChapman EM, Wang XF: Smads bind directly to the Jun family of AP-1 transcription factors. Proc Natl Acad Sci U S A 1999, 96: 4844-4849

56. Yan $\mathrm{X}$, Xiong $\mathrm{X}$, Chen Y-G: Feedback regulation of TGF- $\beta$ signaling. Acta Biochim Biophys Sin 2018, 50:37-50

57. Ji Z, He L, Regev A, Struhl K: Inflammatory regulatory network mediated by the joint action of NF-kB, STAT3, and AP-1 factors is involved in many human cancers. Proc Natl Acad Sci U S A 2019, 116:9453

58. Tang X, Sun L, Jin X, Chen Y, Zhu H, Liang Y, Wu Q, Han X, Liang J, Liu X, Liang Z, Wang G, Luo F: Runt-related transcription factor 1 regulates LPS-induced acute lung injury via NF- $\kappa$ B signaling. Am J Respir Cell Mol Biol 2017, 57:174-183

59. Bellissimo DC, Chen C-h, Zhu Q, Bagga S, Lee C-T, He B, Wertheim GB, Jordan M, Tan K, Worthen GS, Gilliland DG, Speck NA: Runx1 negatively regulates inflammatory cytokine production by neutrophils in response to Toll-like receptor signaling. Blood Adv 2020, 4:1145-1158

60. Thomas G: Furin at the cutting edge: from protein traffic to embryogenesis and disease. Nat Rev Mol Cell Biol 2002, 3: $753-766$

61. Dubois CM, Blanchette F, Laprise MH, Leduc R, Grondin F, Seidah NG: Evidence that furin is an authentic transforming growth factor-betal-converting enzyme. Am J Pathol 2001, 158:305-316

62. Gharib SA, Johnston LK, Huizar I, Birkland TP, Hanson J, Wang Y, Parks WC, Manicone AM: MMP28 promotes macrophage polarization toward M2 cells and augments pulmonary fibrosis. J Leukoc Biol 2014, 95:9-18 